$1-1-1945$

\title{
The comparative value of different test organisms in the microbiological assay of $\mathrm{B}$ vitamins
}

Leon H. Leonian

Virgil Greene Lilly

Follow this and additional works at: https://researchrepository.wvu.edu/ wv_agricultural_and_forestry_experiment_station_bulletins

\section{Digital Commons Citation}

Leonian, Leon H. and Lilly, Virgil Greene, "The comparative value of different test organisms in the microbiological assay of B vitamins" (1945). West Virginia Agricultural and Forestry Experiment Station Bulletins. 319.

https://researchrepository.wvu.edu/wv_agricultural_and_forestry_experiment_station_bulletins/322 


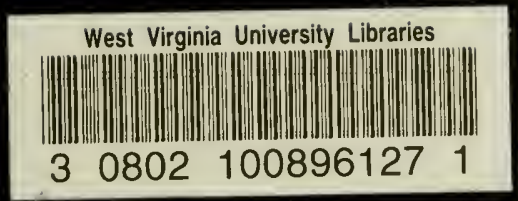


Digitized by the Internet Archive in 2010 with funding from

Lyrasis Members and Sloan Foundation 


\title{
THE COMPARATIVE VALUE OF DIFFERENT TEST ORGANISMS IN THE MICROBIOLOGICAL ASSAY OF B VITAMINS
}

\author{
BY \\ LEON H. LEONIAN \\ AND \\ VIRGIL GREENE LILLY
}




\section{TABLE OF CONTENTS}

\section{Page}

Introduction …

Reference List of Microbiological Assay Methods..............-....... 6

Materials and Methods

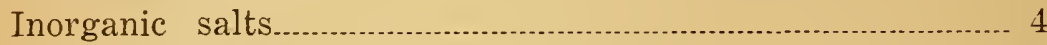

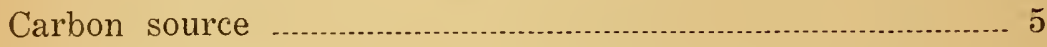

Nitrogen source ……

Agitation … - .

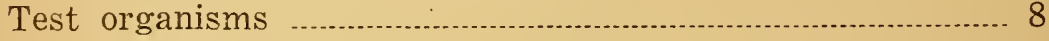

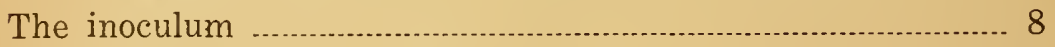

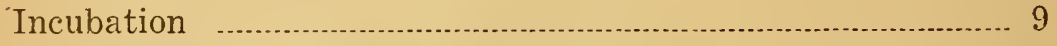

Estimation of growth

Preparation of sample for assay..............................................10

Vitamins assayed:

Thiamin _...

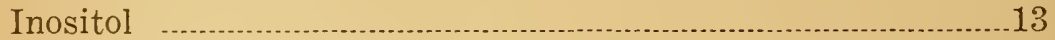

Pantothenic acid ……........................ 15

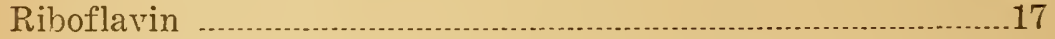

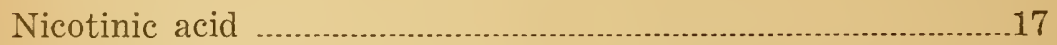

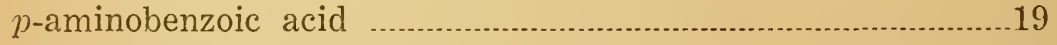

Pyridoxin …

Biotin ……

Discussion ………

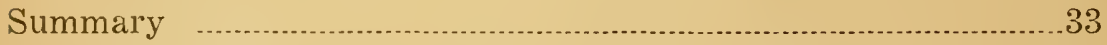

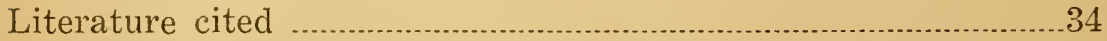




\title{
The Comparative Value Of Different Test Organisms In The Microbiological Assay Of B Vitamins
}

\author{
Leon H. Leonian* and Virgil Greene Lilly
}

\section{INTRODUCTION}

Most investigators engaged in microbiological assays have $M$ been satisfied to use but one organism for testing a specific vitamin; comparatively little attention has been given to the use of many test organisms to assay one vitamin in a given substance. Because an organism may require an exogenous supply of a certain vitamin before it can grow, it does not necessarily follow that no other compound may be substituted for that particular vitamin; there are a number of compounds ("vitamers" or "isotels") that are capable of such substitution. For instance, Snell, Guirard, and Williams (18) and Snell (19) have shown that Lactobacillus casei, which requires pyridoxin for growth, will respond just as well if another substance, "pseudopyridoxin," is substituted. Furthermore, they state that Streptococcus lactis $R$ does not seem to grow in the presence of unheated, synthetic pyridoxin but requires the "pseudopyridoxin," which is formed either by autoclaving pyridoxin with certain amino acids or by the passage of this vitamin through the body of animals. It follows that for $S$. lactis $R$ the "pseudopyridoxin" is a true vitamin, not a "vitamer." Burk and Winzler (4) have shown that three apparently distinct compounds, "miotin, rhiotin, tiotin," can replace biotin in the nutrition of some organisms. Melville, Dittmer, Brown, and du Vigneaud (15) applied the procedure devised for the hydrogenolysis of organic sulfides to biotin methyl ester and obtained a compound which they named desthiobiotin. This substance was found to be as active for a strain of Saccharomyces cercvisiae as biotin itself, but was unable to replace biotin for Lactobacillus casei.

Bovarnick (2) showed that heating an asparagine-glutamate mixture endowed it with the property of supporting growth of several nicotinamide-requiring microörganisms. In a recent publication (3) she has shown that the growth-promoting property of heated asparagine-glutamate mixtures is due to nicotinamide. Here is an interesting case of vitamin formation. Isbell, Wooley, Butler, and Sebrell (10) found that nicotinic acid was unreliable for the standard curve of Shigella paradysenteriae, and that nicotinamide gave much better results. It is a well-known fact that $\beta$-alanine replaces pantothenic acid for many organisms and may well be considered a "vitamer." The specific action of thiamin

"Deceased June 7, 1945 
moieties, pyrimidine and thiazole, has been studied extensively and is too well known to need any discussion here, except to point out that most microbiological assays for thiamin use test organisms that respond not only to the intact thiamin molecule but to either one or both of the moieties as well. Tatum and Beadle (21) found that large amounts of acetyl-p-aminobenzoic acid and $p$ nitrobenzoic acid could replace $p$-aminobenzoic acid, to a limited extent, in the growth of their Neurospora crassa mutant. Other related compounds, such as 0 - and $m$-aminobenzoic acids, were found to be much less effective.

In view of the foregoing survey, it is obvious that our concept of vitamins and of microbiological assays may have to be subjected to a certain amount of revision. One of the purposes of this work is to distinguish the vitamin effect from the "vitamer" or "isotel" effect whenever possible. It is realized that the solution of such a complex problem must of necessity involve a very large number of test organisms and very extensive research in nutrition. The present work is merely a small step in that direction.

The second objective of this wurk is to bring together into one publication the more promising methods of microbiological assay. Some of the techniques outlined here deviate but slightly from standard methods now in use; others are improved, and many are new. An attempt has been made to clarify the technique so as to spare the reader certain perplexities that always arise when authors take it for granted that the readers are as familiar as they are with "routine" biological or chemical methods.

A Review of Microbiological-assay Methods-A completè review of the literature is beyond the scope of this work; only the more representative references are presented. These are classified and arranged in tabular form (Table 1) for the sake of simplicity and convenience.

\section{MATERIALS AND METHODS}

The Inorganic Salts-The employment of numerous and unrelated organisms precludes the possibility of developing a universal medium. The food constituents which are least affected by the specific requirements of the test organisms are the mineral elements. Therefore, unless otherwise stated, the composition and the quantity of the inorganic salts used throughout this work are as follows:

For yeasts and filamentous fungi

For bacteria

\begin{tabular}{|c|c|}
\hline $\mathrm{KH}_{2} \mathrm{PO}$ & $1 \mathrm{~g}$. in $1,000 \mathrm{ml}$ \\
\hline $\mathrm{MgSO}$ & $0.5 \mathrm{~g} . \quad$, \\
\hline $\mathrm{Fe}$ & 0.0002 g. $\quad "$ \\
\hline $\mathrm{Zn}$ & $0.0002 \mathrm{~g}$. \\
\hline $\mathrm{Mn}$ & $0.0001 \mathrm{~g}$. \\
\hline
\end{tabular}

$0.5 \mathrm{~g}$. in $1,000 \mathrm{ml}$.

$0.25 \mathrm{~g}$.

$0.0002 \mathrm{~g}$.

$0.0002 \mathrm{~g}$.

$0.0001 \mathrm{~g}$. 
The Source of Carbon-Dextrose has been used almost exclusively as the source of carbon at the rate of 25 grams per liter for yeasts and filamentous fungi (Phycomyces blakesleeanus, 50 $\mathrm{gm}$.), and 20 grams for bacteria. In the case of Lactobacillus casei and $L$. arabinosus both 10 and 20 grams of dextrose have been used. Sucrose was substituted for dextrose for Rhizobium trifolii 205.

The Source of Nitrogen-Casein hydrolysate was found to be the most satisfactory source of nitrogen. It may be purchased already prepared, or it may be prepared in the laboratory. The writers followed the latter procedure. The SMACO vitamin-test casein was repeatedly precipitated according to the method of Landy and Dicken (14): One liter of distilled water was brought to a temperature of $50^{\circ} \mathrm{C} . ; 100$ grams of casein was added gradually and stirred for 30 minutes. Three grams of sodium bicarbonate was dissolved in a small amount of water and added to the casein solution, stirring constantly. If necessary, more water was added to dissolve all the casein. The solution was adjusted to $\mathrm{pH} 4.6$ by using 10 percent hydrochloric acid; the casein precipitate was allowed to settle and was removed. This procedure was repeated four times. The writers then continued by following a modified procedure for hydrolyzing casein: 200 grams of precipitated casein was refluxed for 15 hours with 2 liters of $6 \mathrm{~N}$ hydrochloric acid. The excess acid was then removed by repeated vacuum distillation. The hydrolysate was next placed in one liter of distilled water and adjusted to $\mathrm{pH} 4$ by concentrated sodium hydroxide. After adding 40 grams of Norit A, the solution was brought to boiling while being stirred constantly and was then filtered through No. 325 Delta filter paper under suction. The Norit was washed with boiling water and the filtrate was added to the casein hydrolysate solution, thus bringing the volume to the original 2,000 milliliters. The $\mathrm{pH}$ was adjusted to $2-3$ and the material was stored in the refrigerator at $0^{\circ} \mathrm{C}$. Ten milliliters of this was equivalent to one gram of casein.

Another method of preparing casein hydrolysate is described bv Krehl, Strong, and Elvejhem (13): 100 grams of casein is twice extracted by stirring 15 minutes with 2 or 3 volumes of 95 percent ethanol and filtered. It is then refluxed over a low flame with concentrated hydrochloric acid for 16 to 20 hours, concentrated to a paste at $70^{\circ}$ to $80^{\circ} \mathrm{C}$. under reduced pressure; 200 milliliters of water is adcled and again concentrated. The residue is dissolved in 700 milliliters of water and adjusted to $\mathrm{pH} 4$. Twenty grams of Norit A is added and stirred for an hour at room temperature. It is then filtered, the $\mathrm{pH}$ adjusted to 6.6 and diluted with distilled water to 1,000 milliliters. Any sediment occurring in this hydrolysate upon standing may be eliminated by autoclaving.

Other sources of nitrogen used in this work consisted of ammonium sulfate, asparagine, and certain amino acids. The amounts and the different combinations of these will be described 


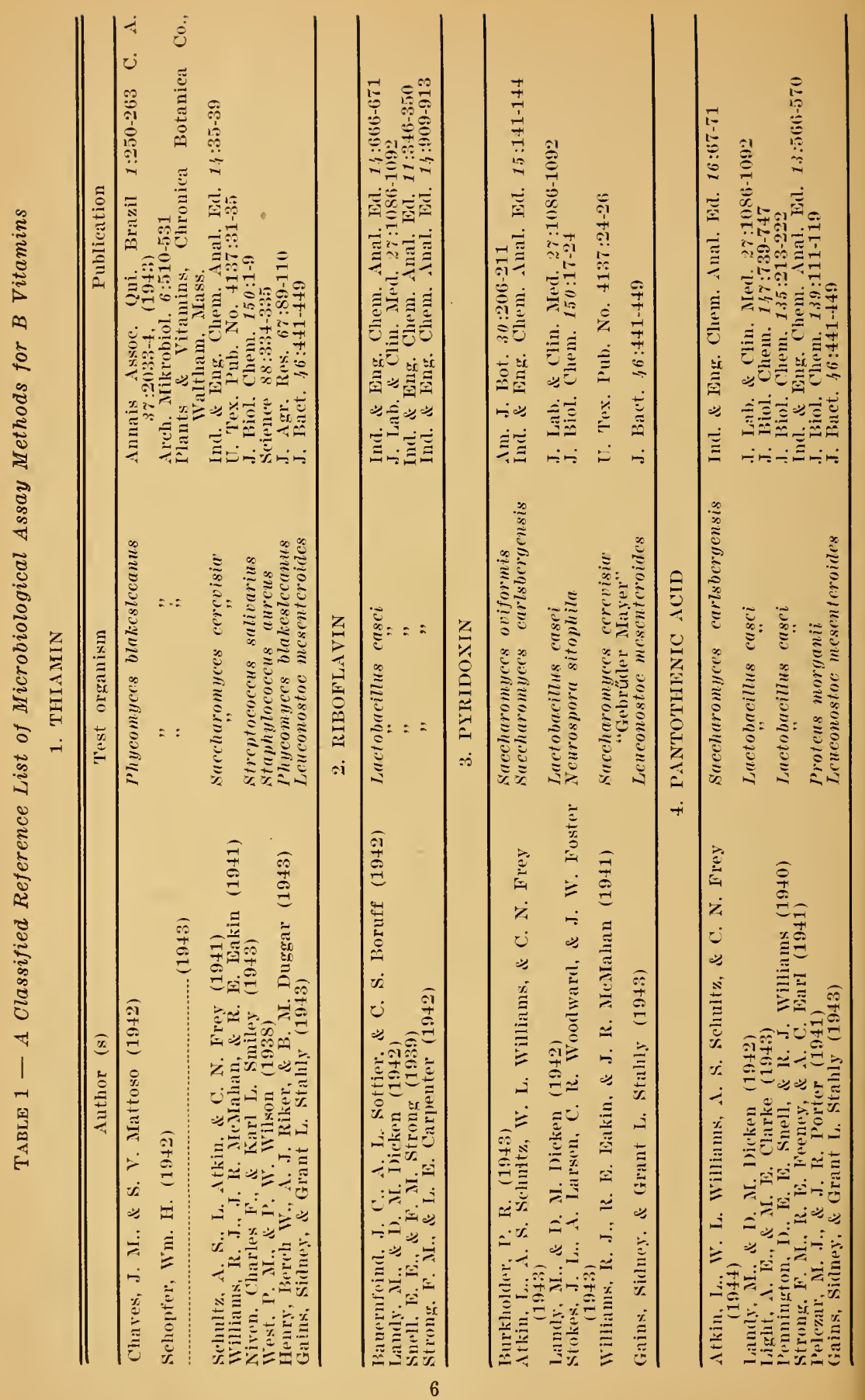




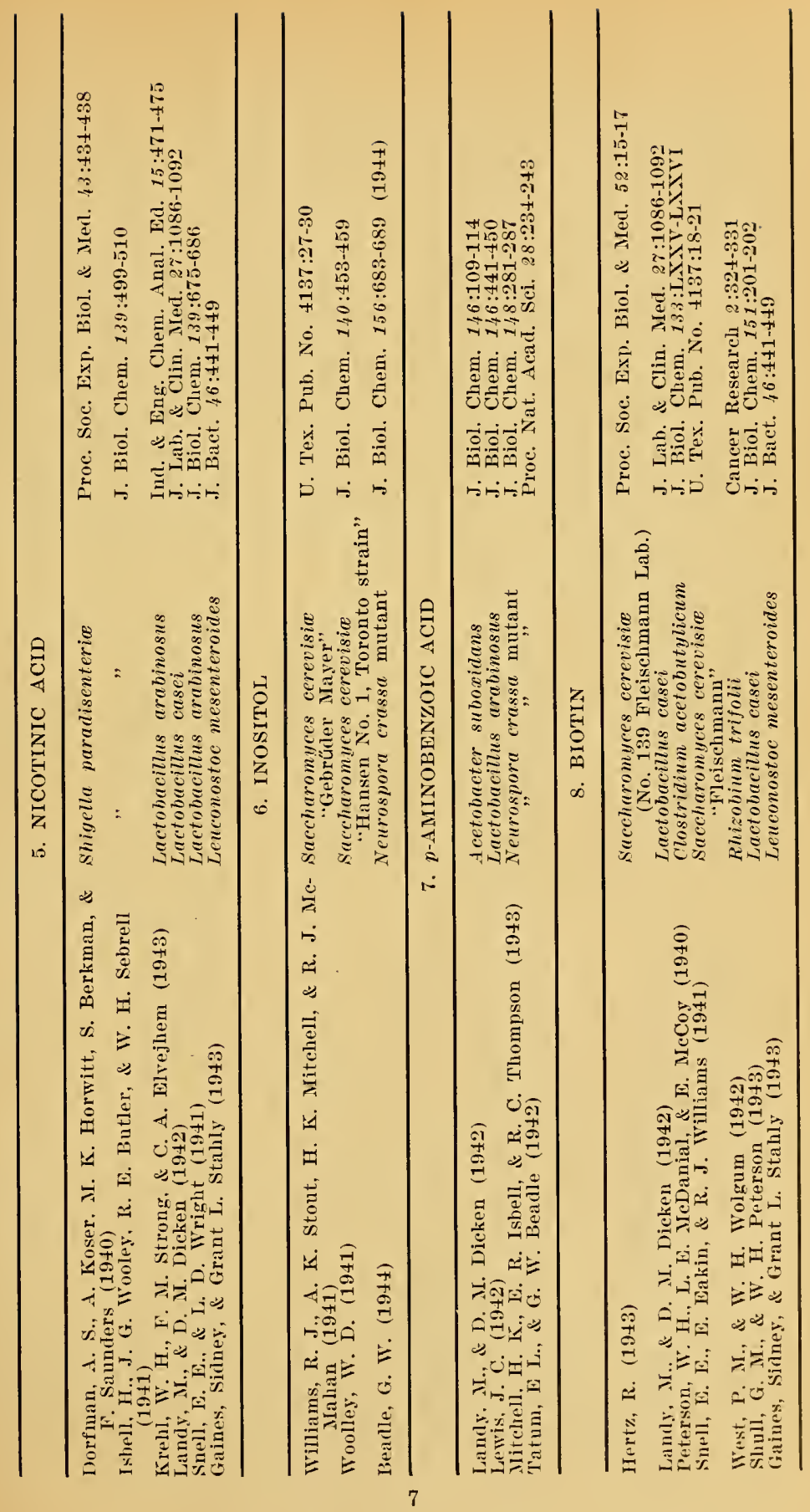


later when the media for the specific test organisms are described. This applies also to the vitamins and other accessory factors.

The Quantity of the Nutrient Solutions-All yeasts and filamentous fungi were grown in 250 milliliter flasks, each containing 25 milliliters of the medium. The bacteria were grown in 125 milliliter flasks each containing 10 miliiliters of the medium.

Agitation: Cultures of Debaryomyces-matruchoti v. subglobosus, Mycoderma valida, Saccharomyces cerevisiae ("Old Process" and "Gebrüder Mayer"), S. carlsbergensis and Zygosaccharomyces marxianus were agitated. The flasks were placed on a flatbed shaking machine which had a 6-inch stroke and made 50 strokes per minute. The shaking machine operated 10 minutes out of every hour; a time clock was used to turn the motor on and off. No filamentous fungi or bacteria were shaken during growth. The effect of shaking on the bacteria was not investigated, with the exception of Rhizobium trifolii 205. Shaking increases the rate of growth of this organism. Single flasks from a series were not removed from the incubator for inspection before the readings were made.

Test Organisms-(See Table 2.)

T.uLE 2 - A List of Test Organisme Used in This Work with Source and Use of Each

\begin{tabular}{|c|c|c|}
\hline Name & Source of culture & Vitamin (s) tested \\
\hline 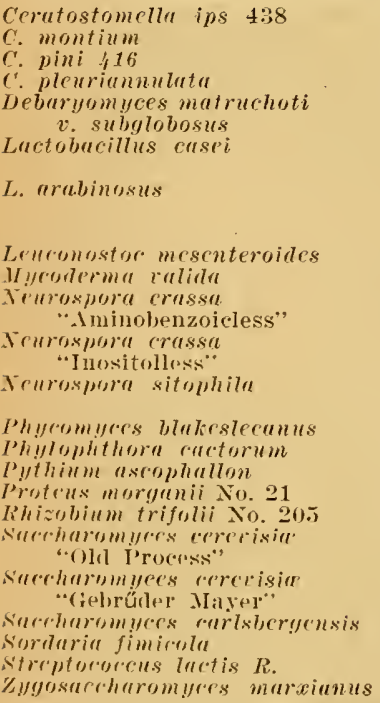 & 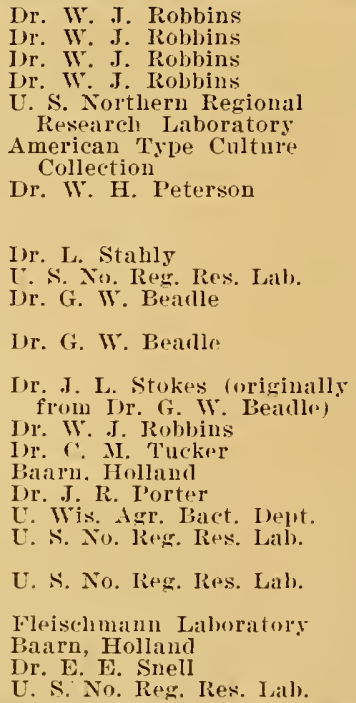 & 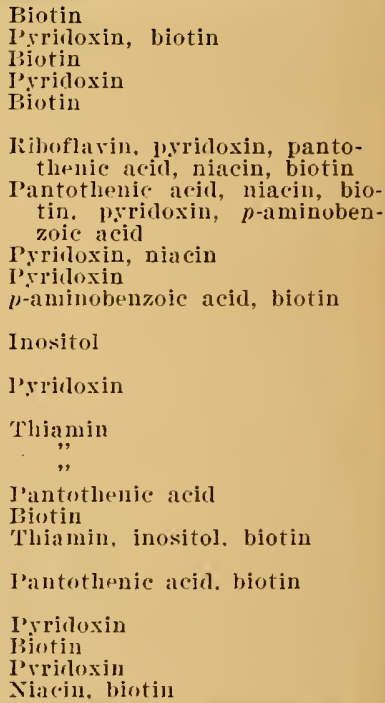 \\
\hline
\end{tabular}

The Inoculum-The filamentous fungi, with the exception of Neurospora crassa, N. sitophila, and Phycomyces blakesleeanus, were grown on nutrient agar in Petri dishes, 20 milliliters per Petri dish; after the colony filled most of the plate, inoculum 
discs were cut all along the edges of the colony by means of a cork borer with an opening of 4 millimeters and one disc was transferred to each flask. This insured inoculum pieces of uniform age and size. This is a desirable, but not necessarily a vital, factor because inoculum pieces of smaller size and older age have given essentially similar results. Spore suspensions also were made in a nutrient solution containing 0.5 percent yeast extract, and incubated overnight at $25^{\circ} \mathrm{C}$. to induce germination. One standardized loopful of this suspension was transferred to each flask. The platinum wire was B \& S 24-gauge, double loop, with an inside diameter of 2.5 millimeters.

The yeast inoculum was obtained from 72-hour-old cultures in the complete yeast medium (liquid). One standardized loopful was used for each flask.

Stock cultures of bacteria were carried in liquid nutrient media containing the necessary vitamins plus 0.5 percent yeast extract. Seventy-two-hour cultures growing in similar media furnished the inoculum at the rate of one loopful per flask. The cumbersome practice of washing and centrifuging the cells before inoculating was found to be entirely unnecessary. The amount of vitamins in one loopful of cell suspension is so infinitesimal that even 10 or more loopfuls fail to induce noticeable growth.

Incubation-Yeasts, filamentous fungi, and Leuconostoc mesenteroides were incubated at $25^{\circ} \mathrm{C}$., Rhizobium trifolii 205 and Streptococcus lactis $\mathrm{R}$ at $30^{\circ} \mathrm{C}$, and the remaining bacteria at $37^{\circ} \mathrm{C}$. The length of the incubation period varied for the different filamentous fungi, but was 72 hours for yeasts (48 hours for $S$. cerevisiae "Old Process" in inositol assay) and for some of the bacteria. Proteus morganii was incubated for only 24 hours, while Leuconostoc mesenteroides and Streptococcus lactis required 4 days to reach their optimum growth.

Estimating the Yield-Nearly all of the filamentous fungi were readily harvested by filtering through a piece of marquisette cloth. Some species of Ceratostomella form an abundance of microconidia and are best harvested by filtering through Alundum crucibles RA-360 under vacuum. The harvested mats of mycelium were dried at $85^{\circ} \mathrm{C}$. for 24 hours and weighed. The yeasts were harvested by filtering through Alundum crucibles when the growth .was heavy; but in case of scanty growth Selas crucibles No. 2001 were used. The sugar of the unused medium in such scanty cultures becomes adsorbed on the large surfaces of the Alundum crucibles and despite repeated washings will remain to influence the final weight. After the weights were recorded, all crucibles were washed, heated in a muffle furnace at $600^{\circ} \mathrm{C}$., cooled, washed three times under suction with distilled water, dried at $85^{\circ} \mathrm{C}$. and weighed. Four hours at $85^{\circ} \mathrm{C}$. sufficed to dry the harvested yeast cells.

A Fisher electrophotometer was used to estimate the amount of growth made by bacteria. 
Extraction of Yeust for Assaying-A commercial yeast, in form of dry flakes, was selected as the material to be assayed for the $B$ vitamins. Acid hydrolysis was found to be the best method for the extraction of inositol, nicotinic acid, and biotin; the remaining vitamins were extracted by autolysis and autoclaving combined. While papain and takadiastase, alone and in combination, were also tried, they were not found to be superior to the method used. The acid hydrolysate was prepared as follows: 20 grams of the dry veast cells were autoclaved for one hour in $\mathrm{N} / 1$ sulfuric acid; barium hydroxide was added to adjust the solution to $\mathrm{pH} \mathrm{4}$, and centrifuged; the supernatant solution was decanted, the precipitated material was washed twice with distilled water, then recentrifuged, and the washings were combined with the original supernatant solution, 95 percent alcohol was added to give a 20 percent alcoholic solution, and the final volume was made to 400 milliliters. One milliliter of this solution was equivalent to 50 milligrams of yeast cells.

The autolysate was prepared as follows: 100 milliliters of water was added to 2 grams of yeast cells and kept under benzene for 24 hours at $37^{\circ} \mathrm{C}$. Benzene was removed in vacuo; the cells were removed by centrifuging, washed twice and centrifuged, and all three supernatant solutions were combined. The yeast cells were then placed in 100 milliliters of distilled water and autoclaved for 15 minutes, centrifuged, washed, and centrifuged again; the supernatant solutions were combined with the autolysate; alcohol was added to make a 20 percent alcoholic solution, and the volume was adjusted to $500 \mathrm{ml}$. One milliliter was equivalent to 4 milligrams of yeast cells. The extracts were stored in brown glass bottles and kept in a refrigerator.

\section{THE EXPERIMENTAL WORK}

\section{THIAMIN ASSAY}

The following organisms were used to determine the amount of thiamin in the yeast sample: Puthium ascophallon, Phycomyces blakesleeanus, and Saccharomyces cerevisiae "Old Process." The first organism must be furnished with the thiamin molecule be- fore it can grow; Phycomyces blakesleeanus grows very well in the presence of pyrimidine and thiazole, while the yeast grows readily when furnished with thiazole only.

Pythium ascophallon-The nutrient medium for this organism had the following constituents:

Inorganic salts

Dextrose

Glycine

all-a-alanine

Arginine hydrochloride

Glutamic acid

Aspartic acid

Biotin

Distilled water

$\mathrm{pH}$ (before autoclaving)

$25 \mathrm{~g}$.

$0.5 \mathrm{~g}$.

0.5

0.5 "

$1.0 "$

$1.0 "$

1 microgram

$1,000 \mathrm{ml}$.

5.5

The incubation period was 10 days. 
While the results recorded in this paper were obtained with the foregoing medium, one may substitute 2 grams of asparagine and 1.2 grams of fumaric acid for the five amino acids, without materially influencing the assay results. In fact, fairly good growth may be obtained in much simpler solutions, but the reproducibility of the results may be less satisfactory. When furnished with the most favorable nutrient medium and a long incubation period the fungus seems to be able to synthesize some unknown accessory factors and thus reduce its erratic behaviors to a minimum.

The amounts of thiamin used for the production of the standard curve were $0.0,0.0125,0.025,0.05,0.1,0.2$, and 0.4 microgram per 25 milliliters (Fig. 1). The amounts of yeast samples to be assayed were $0.05,0.1,0.2$, and 0.4 milligram per 25 milliliters of medium.

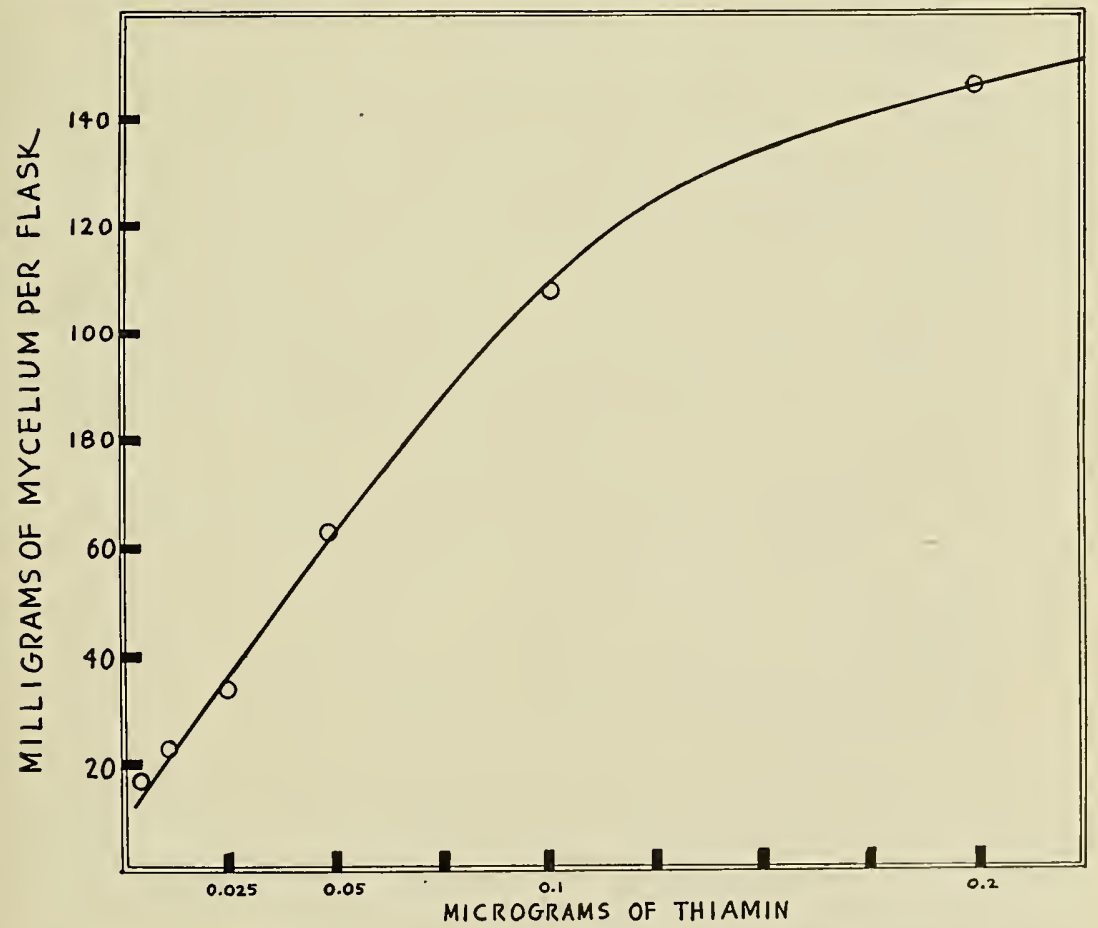

FIg. 1-Thiamin curve. Pythium ascophallon test organism

Phycomyces blakesleeamus-This is the most widely used fungus for determination of thiamin. It is less variable than many others, and the reproducibility of its results leaves little to be desired. Unfortunately it responds just as well to thiamin moieties as it does to the thiamin molecule itself. Where free moieties are not present, as in the yeast sample, this fungus is a very satisfactory test organism. 
Both spore suspension and bits of young mycelium have been used as inoculum. In case of the former method the spores were suspended in a nutrient solution containing 0.5 percent of yeast extract; transfers were made after the spores germinated. This precaution is necessary because the spores of this fungus do not germinate readily in most synthetic solutions. Cultures furnishing spores were grown in the light in order to encourage sporangium formation.

The nutrient medium for Phycomyces blakesleeanus had the following composition:

\author{
Inorganic salts \\ Dextrose \\ Casein hydrolysate \\ equivalent to \\ Fumaric acid \\ Sodium carbonate \\ Distilled water
}

$50 \mathrm{gm}$.

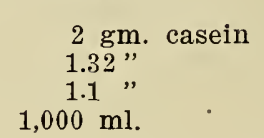

The foregoing substances, with the exception of the inorganic salts, were dissolved in 500 milliliters of water, 5 grams of Norit A was added, and the solution was brought to boil with constant stirring. The suspension was filtered, the inorganic salts added, the volume made up to 1,000 milliliters, and the reaction adjusted to $\mathrm{pH} 5.5$.

The incubation period was 7 days; the amounts of thiamin for the production of the standard curve were $0.0,0.0125,0.025$, $0.05,0.1,0.2$, and 0.4 microgram per 25 milliliters of medium. The amount of yeast for assaying was $0.05,0.1,0.2,0.4$, and 0.8 milligram per 25 milliliters of the medium.

Saccharomyces cerevisiae, "Old Process"-This organism was grown in a solution of the following composition:

$\begin{array}{lc}\text { Inorganic salts } & \\ \text { Dextrose } & 25 \mathrm{gm} . \\ \text { Casein hydrolysate } & 2 \text { " casein } \\ \text { equivalent to } & 1.32 \mathrm{gm} . \\ \text { Fumaric acid } & 1.12 "\end{array}$

Before the addition of the inorganic salts and the vitamins the solution was treated with Norit $A$. The reaction of the medium was adjusted to $\mathrm{pH} 5.0$ and the vitamins were added at the rate of 100 micrograms each of pyridoxin and pantothenic acid, 1 microgram of biotin, and 10 milligrams of inositol per 1,000 milliliters of the medium.

The incubation period was 72 hours. The amounts of thiamin for the production of the standard curve were $0.0,0.025,0.05$, $0.1,0.2,0.4$, and 0.8 microgram per 25 milliliters of medium. The amounts of yeast to be assayed were $0.075,0.15,0.3$, and 0.6 milligram per 25 milliliters of the medium.

Table 3 gives the assay values for thiamin: 
T.ıвL 3 - Thiamin-hydrochloride Assay Values as Determined by Three Test Organisms

\begin{tabular}{cc}
\hline \hline Test organism & Micrograms of thianin per gram \\
\hline Pythium ascophatlon & $520 \pm 38$ \\
Phycomyces blakesleeanus & $506 \pm 26$ \\
Saccharomyccs cercyisia & $529 \pm 33$ \\
\hline "Old Process" & \\
\hline
\end{tabular}

\section{INOSITOL ASSAY}

The test organisms for inositol were Saccharomyces cerevisiae, "Old Process," and the "inositolless" mutant strain of Neurospora crassa which was obtained through the courtesy of Dr. G. W. Beadle (1).

Saccharomyces cerevisiae, "Old Process"-The yeast medium (see page 12) was used; it contained also 100 micrograms of thiamin, pyridoxin, pantothenic acid, and one microgram of biotin free acid per liter. In addition 0.125 gram of yeast nucleic acid was added to the medium. The amounts of inositol for the production of the standard curve were $0.0,2.50,3.75,5.00,7.50$, $10.0,15.0,20.0$, and 25.0 micrograms per flask of 25 milliliters of nutrient solution (Fig. 2). The amounts of yeast to be assayed were $3.125,6.25,12.50$, and 25.0 milligrams per flask. Both the dry weight of the yeast cells and photometric readings were employed to estimate the yield. The cells of S. cerevisiae "Old Pro-

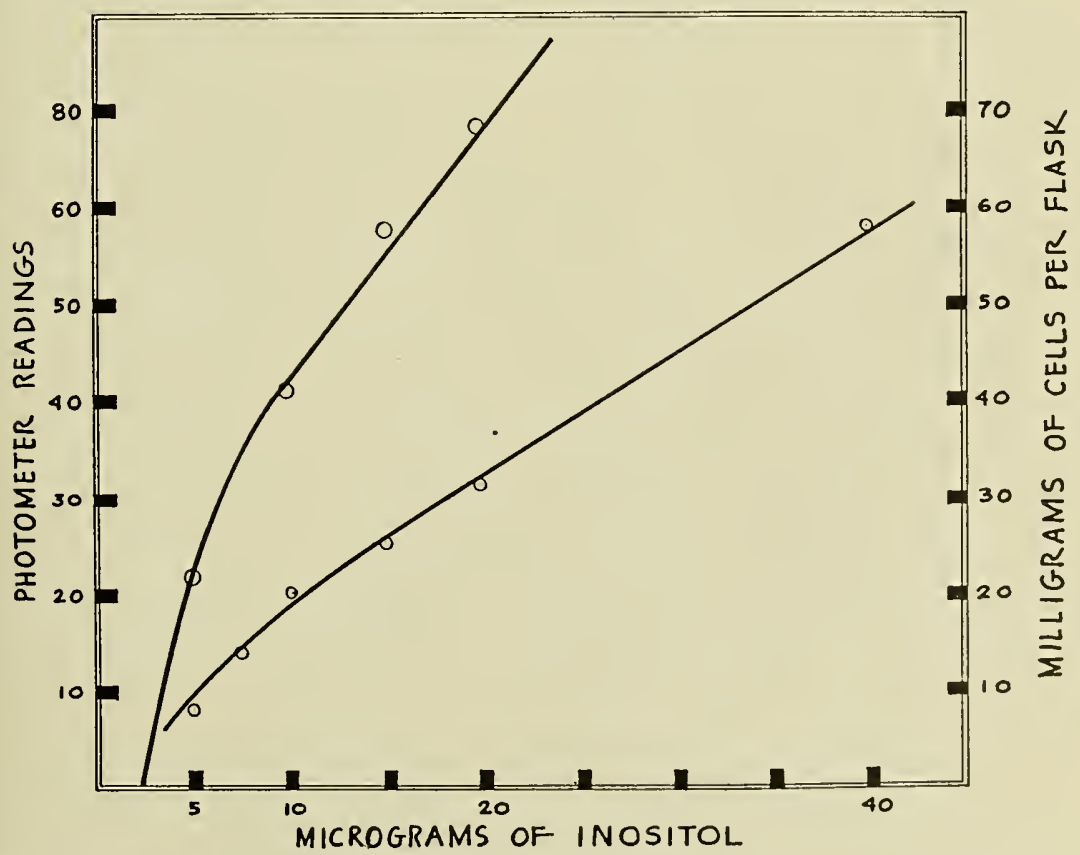

FIg. 2-Inositol curves. Saccharomyces cerevisiae "Old Process" test organism 
cess" did not disperse well in the nutrient solution but tended to clump; therefore we prefer the assay value calculated from the dry-weight determinations.

Neurospora crassa, "Inositolless"-The medium used was the same as for S. cerevisicue, "Old Process," except that it contained one microgram of biotin per liter as the only supplement. The amounts of inositol for the production of the standard curve were $0.0,4.0,8.0,16.0,32.0$, and 64.0 micrograms per flask of 25 milliliters of nutrient solution (Fig. 3). The time of incubation was 5 days, the temperature $25^{\circ} \mathrm{C}$. The amounts of yeast to be assayed

TABLE 4 - Inositol Assay Values as Determined by Two Test Organisms

\begin{tabular}{lc}
\hline \hline Test organisms & Micrograms of inositol per gram \\
\hline Saccharomyces cerevisice "Old Process" & $1.333 \pm 115 *$ \\
Neurospora crassa, "Inositolless" & $1,605 \pm 102$ \\
\hline * The assay ralue as determined by photometer readings was $1633 \pm 75$.
\end{tabular}

were $3.125,6.25,12.5$, and 25.0 milligrams per flask. Under our conditions this organism proved to be somewhat more sensitive to inositol than reported by Beadle (loc. cit.). This is a very satisfactory organism because no growth at all appears in the absence of inositol, and the fungus cannot be induced to grow without it, regardless of time and size of inoculum.

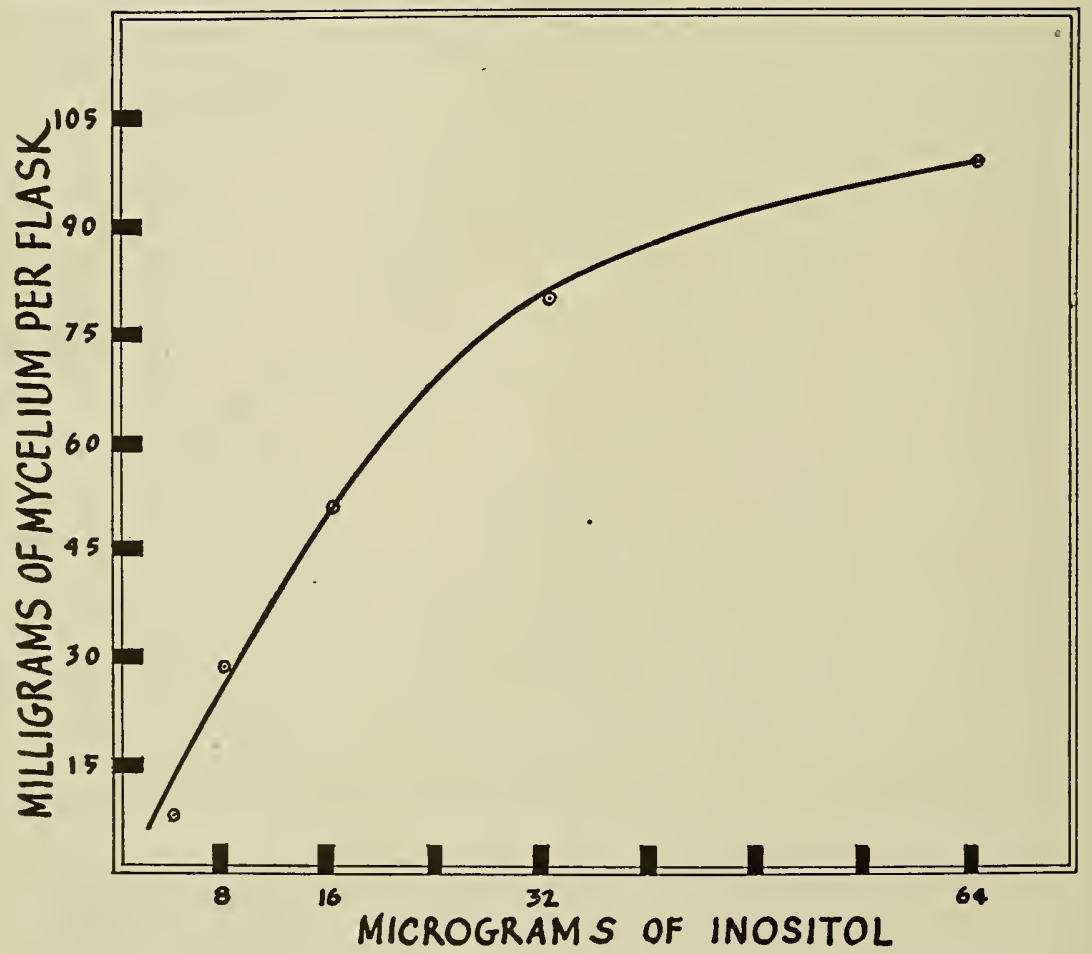

Frg. 3-Inositol curve. Neurospora crassa "inositolless" test organism 
The following organisms were used to determine the amount of pantothenic acid in the yeast sample: Lactobacillus casei, $L$. arabinosus, Proteus morganii, and Saccharomyces cerevisiae "Gebrüder Mayer."

Lactobacillus casei-The nutrient medium of Landy and Dicken, (14) with some modifications, was used for this organism. It contained the following substances:

\begin{tabular}{|c|c|c|}
\hline Dextrose & $20 \mathrm{~g}$. & \\
\hline Casein hydrolysate equivalent to & 5 g. casein & \\
\hline Sodium acetate $\left(3 \mathrm{H}_{2} \mathrm{O}\right)$ & $20 \mathrm{~g}$. & \\
\hline Cystine & $0.2 \mathrm{~g}$. & \\
\hline Tryptophane & $0.1 \mathrm{~g}$. & \\
\hline Adenine & $5 \mathrm{mg}$. & \\
\hline Guanine & $5 \mathrm{mg}$. & \\
\hline Uracil & $5 \mathrm{mg}$. & \\
\hline Xanthine & $5 \mathrm{mg}$. & \\
\hline Thiamin & 100 micrograms & \\
\hline Riboflavin & 200 & \\
\hline Pylidoxin & 400 & \\
\hline Nicotinic acid & 200 & \\
\hline Biotin & 2 & \\
\hline Folic-acid concentrate* & 40 & of $5 \%$ folic acid \\
\hline $\begin{array}{l}\text { Distilled water } \\
\mathrm{pH}\end{array}$ & $\begin{array}{l}1,000 \mathrm{ml} . \\
6.6-6.8\end{array}$ & \\
\hline
\end{tabular}

* Obtained through the courtesy of Dr. R. J. Williams.

Before the addition of the inorganic salts cystine, tryptophane, the vitamins, and the purines, the nutrient solution was treated with Norit A.

Adenine, guanine, and uracil were first placed in a small amount of water; just enough hydrochloric acid was added to dissolve them. Xanthine was placed in a small amount of water, and just enough sodium hydroxide was added to dissolve it.

The amounts of calcium pantothenate for the production of the standard curve were $0.0,0.02,0.04,0.08,0.16,0.32$ and 0.64 microgram per 10 milliliters. The amounts of yeast to be assayed were $0.4,0.8,1.6,3.2$, and 6.4 milligrams per 10 milliliters.

Lactobacillus arabinosus-The nutrient medium was the same as for L. casei, except that the folic-acid concentrate was omitted.

Proteus morganii-The nutrient medium for this organism was prepared in two parts, $\mathrm{A}$ and $\mathrm{B}$, as follows:

Solution $A$.

Dextrose

Nicotinic acid

Varying amounts of pantothenic acid

Distilled water
$20 \mathrm{~g}$.

$1 \mathrm{mg}$.

$500 \mathrm{ml}$. 
Solution $B$

$\mathrm{KH}_{2} \mathrm{PO}_{4}$

$\mathrm{MgSO}$.

Casein hydrolysate equivalent to

Cystine

Tryptophane

$\mathrm{Fe}$

$\mathrm{Zn}$

Mn

Distilled water

$\mathrm{pH}$
$5 \mathrm{~g}$.

$0.25 \mathrm{~g}$.

2 grams of casein

$100 \mathrm{mg}$.

$100 \mathrm{mg}$.

$0.0002 \mathrm{~g}$.

$0.0002 \mathrm{~g}$.

$0.0001 \mathrm{~g}$.

$500 \mathrm{ml}$.

7.4

The solution $\mathrm{A}$ is distributed at the rate of 5 milliliters per flask; the solution B is distributed at the same rate in another series of flasks. After sterilization in the autoclave the contents of one flask containing solution A are poured into a flask which contains solution B. This procedure prevents the caramelization of sugar caused by high $\mathrm{pH}$ and gives a colorless solution. Any precipitates that may form will disappear shortly after mixing the two solutions.

The amounts of calcium pantothenate for the production of the standard curve were $0.0,0.002,0.004,0.008,0.016,0.032$, 0.064 , and 0.128 microgram per flask (final volume 10 milliliters).

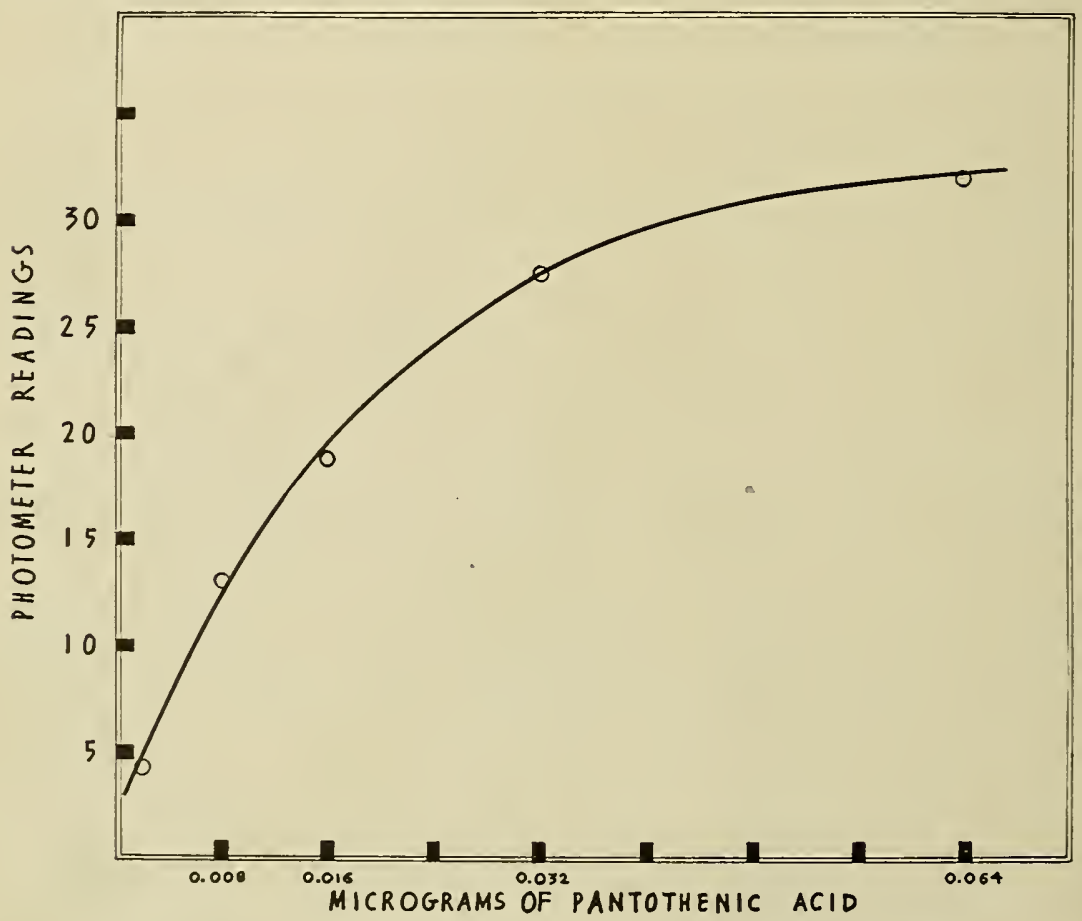

FIG. 4-Pantothenic-acid curve. Proteus morganii test organism 
(See Fig. 4.) The amounts of yeast to be assayed were $0.04,0.08$, $0.16,0.32$ and 0.64 milligram per flask.

Saccharomyces cerevisiae, "Gebrüder Mayer"-The medium and vitamins used for this organism were the same as those employed in case of $S$. cerevisiae "Old Process," except that the amounts of calcium pantothenate for the production of the standard curve were $0.0,0.125,0.25,0.5,0.75,1.0$, and 1.25 micrograms per flask of 25 milliliters. The amounts of yeast to be assayed were $1,2,4,6$, and 8 milligrams per flask (Table 5).

\begin{tabular}{lc}
$\begin{array}{c}\text { T.ıBLE } 5 \text { - Calcium Pantothenate Assay Values as } \\
\text { Determined by Four Test Organisms }\end{array}$ \\
\hline Test organism & Micrograms per gram of seast \\
\hline Lactobacillus casei & $61 \pm 4.5$ \\
Lactobacillus arabinosus & $65 \pm 2.5$ \\
Saccharomyces cerevisice & $64 \pm 4.0$ \\
"Groteurüder Maver" & $37 \pm 1.4$ \\
\hline
\end{tabular}

\section{RIBOFLAVIN ASSAY}

The test organism for riboflavin assay was Lactobacillus casei, and the medium used was the same as for pantothenic-acid assay. The amounts of riboflavin for the production of standard curve were $0.0,0.02,0.04,0.08,0.16,0.32$, and 0.64 microgram per flask of 10 milliliters of medium. The amounts of yeast used for assaying were $0.4,0.8,1.2,1.6,2.4$, and 3.2 milligrams per flask (Table 6).

$$
\begin{gathered}
\text { TABLe } 6-\text { Riboflavin Assay Value as Determined by } \\
\text { Lactobacillus casei }
\end{gathered}
$$

$\frac{\overline{\text { Micrograms of riboflavin per gram of seast }}}{73 \pm 3}$

\section{NICOTINIC-ACID ASSAY}

The following organisms were used for nicotinic-acid assay: Lactobacillus casei, L. arabinosus, Leuconostoc mesenteroides, and Zygosaccharomyces marxianus.

Lactobacillus casei-The medium was the same as that used previously for this organism. The amounts of nicotinic acid for the production of standard curve were $0.0,0.01,0.02,0.04,0.08$, 0.16 , and 0.32 microgram per flask of 10 milliliters of nutrient solution. The amounts of yeast to be assayed were $0.1,0.2,0.4$, and 0.8 milligram per flask.

Lactobacillus arabinosus-The medium was the same as that used for $L$. casei except that folic acid was omitted. The range of nicotinic acid for the production of the standard curve was 0.0 , $701,0.02,0.04,0.08,0.16,0.32$, and 0.64 microgram per flask ${ }^{0}>0$ milliliters of nutrient medium. The yeast to be assayed was 
used at the rate of $0.1,0.2,0.4,0.8,0.16$, and 0.32 milligram per flask.

Leuconostoc mesenteroides-The medium was the same as that used for $L$. casei, except that no folic acid was added. The range of nicotinic acid for the production of the standard curve was $0.0,0.025,0.05,0.1,0.2,0.4$, and 0.8 microgram per flask of 10 milliliters of solution. The yeast to be assayed was at the rate of $0.1,0.2,0.4$, and 0.8 milligram per flask.

$Z$ ygosaccharomyces marxianus-The yeast medium was used for this organism. Thiamin, pyridoxin, pantothenic acid, inositol, and biotin were the vitamins added in the usual quantities. The $\mathrm{pH}$ of the medium was 5.0. The range of nicotinic acid for the production of the standard curve was $0.0,0.05,0.075,0.1,0.15$, $0.2,0.3,0.4$, and 0.6 microgram of nicotinic acid per flask of 25 milliliters of medium (Fig. 5). The amounts of yeast to be assayed were $0.2,0.4,0.8$, and 1.6 milligrams per flask.

Table 7 gives the assay figures.

TABLE 7 - Nicotinic-acid Assay Values as Determined by

Four organisms

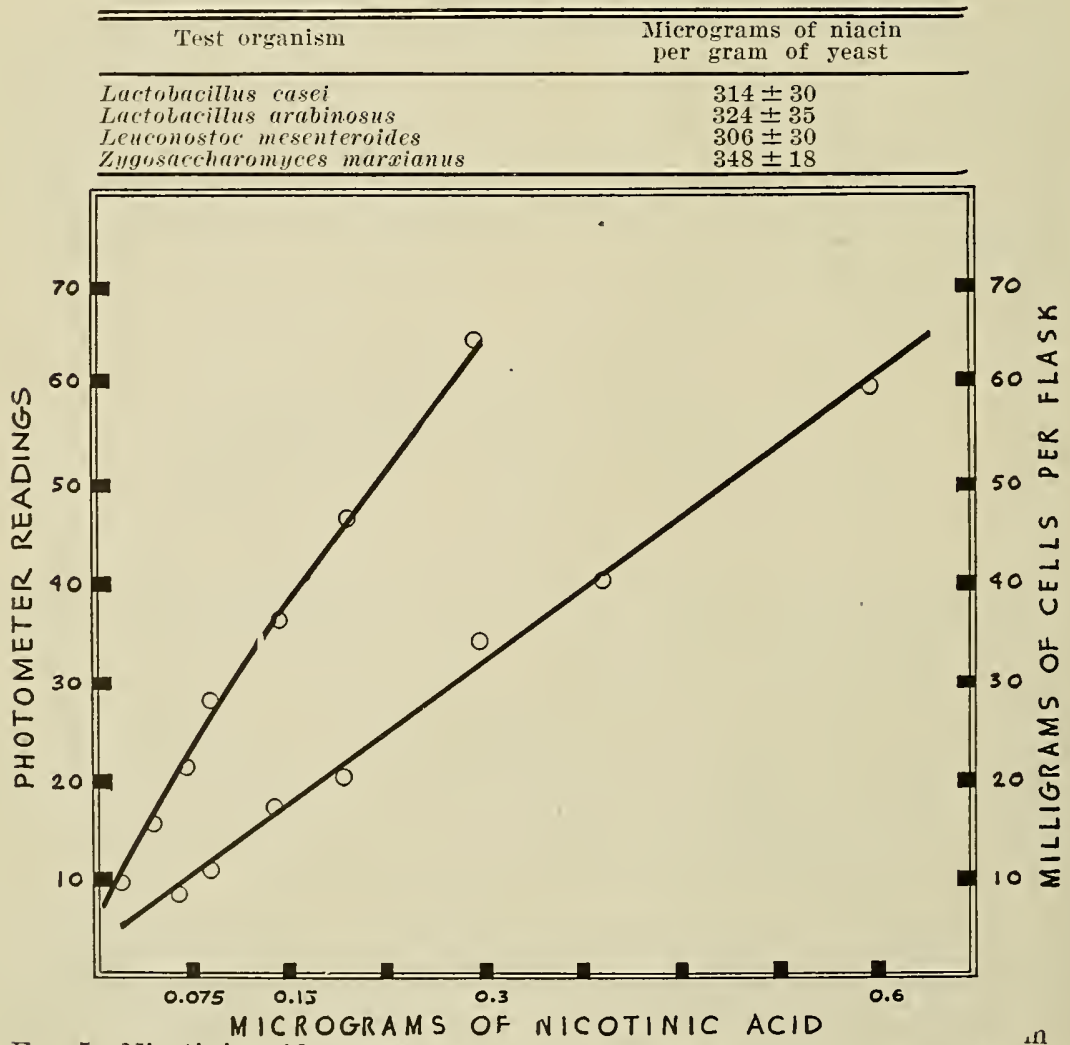

FIG. 5-Nicotinic-acid curves. Zygosaccharomyces marxianus test orga. 


\section{p-AMINOBENZOIC-ACID ASSAY}

The Neurospora crassa mutant " 1633 " of Tatum and Beadle was used for assaying $p$-aminobenzoic acid. The medium was the one used for yeasts, with the $\mathrm{pH}$ adjusted to 5.5, and with 1 microgram of biotin added to each 1,000 milliliters of the solution. The amounts of $p$-aminobenzoic acid for the production of the standard curve were $0.0,0.05,0.1,0.2,0.4$, and 0.8 microgram per flask of 25 milliliters of medium (Fig. 6). The amounts of yeast to be assayed were $2,3,4,6$, and 8 milligrams per flask.

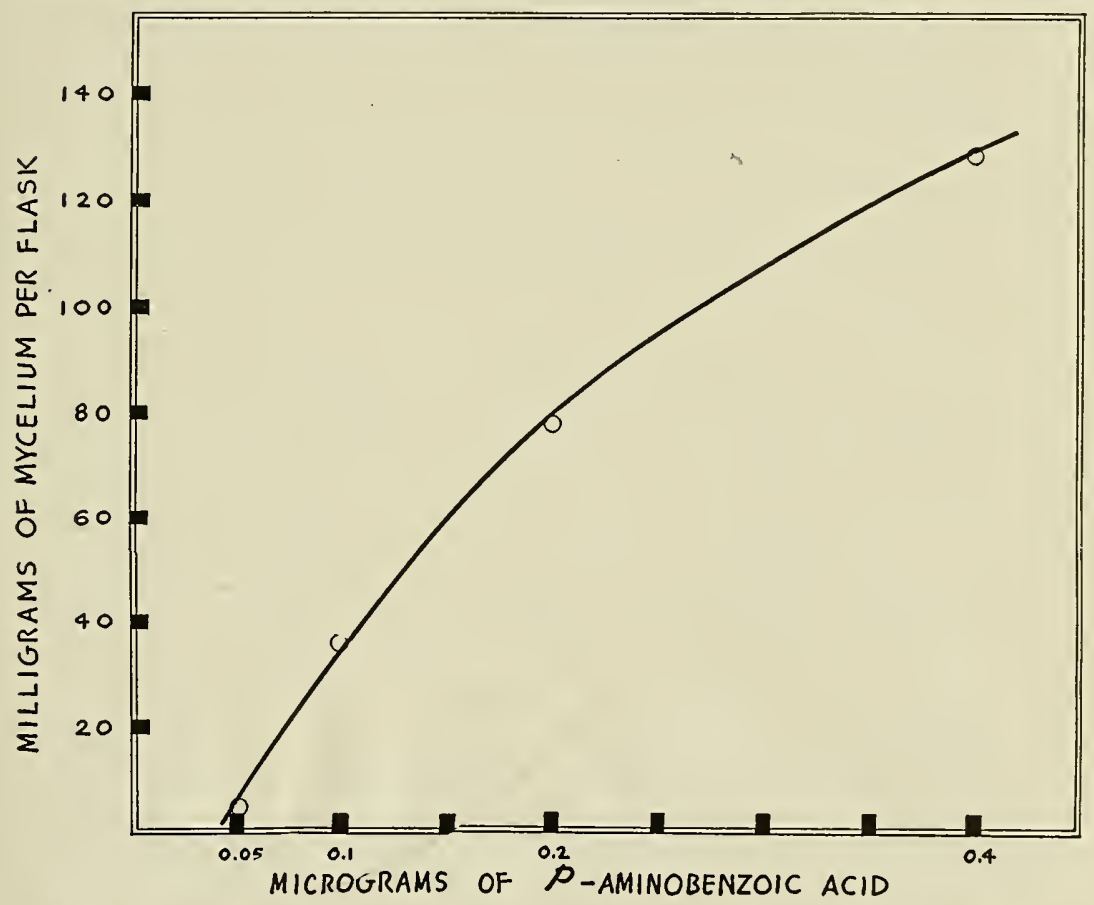

FIG. 6-o -aminobenzoic-acid curve. Neurospora crassa test organism

Care must be exercised to see that the $\mathrm{pH}$ of the standard and unknown series is the same, since the availability of $p$-aminohenzoic acid to this strain of Neurospora crassa under these conditions has been shown to be a function of the $\mathrm{pH}$ of the medium (23).

The incubation period was 72 hours.

Lactobacillus arabinosus-The writers failed to obtain satisfactory results with this organism by the use of standard methods because a trace of $p$-aminobenzoic acid left in casein hydrolysate induced too much growth in the controls, and when by a more rigorous Norit treatment all of this vitamin was eliminated, the organism failed to grow even in the presence of added $p$-aminobenzoic acid. An attempt was made to "neutralize" the vitamin 
left in casein hydrolysate by means of sulfathiazole, but the growth curve obtained was too variable to be of much value. The problem was then attacked from a different angle: two series of nutrient solution were prepared, both containing a constant amount of sulfathiazole. Varying amounts of $p$-aminobenzoic acid were added to one series, and varying amounts of yeast were added to the other. These were inoculated with $L$. arabinosus and incubated. The cultures were examined at various intervals. Growth occurred in the presence of higher amounts of $p$-aminobenzoic acid or of yeast, but there was no growth in the lower concentrations of these. Therefore it was assumed that the $p$-aminobenzoic-acid content of the lowest members of each series showing growth contained equivalent amounts of this vitamin. It was further observed that the amounts of the vitamin or of the yeast necessary to overcome the bacteriostatic effect of sulfathiazole decreased with the length of incubation period. Consequently as time went on and more flasks showed growth, additional data were obtained. Table 8 gives the results of a number of such experiments.

TABle 8 - Amount of p-aminobenzoic Acid in Yeast as Determined by Aid of the Bacteriostatic Effect of Sulfathiazole

\begin{tabular}{|c|c|c|c|c|}
\hline $\begin{array}{l}\text { Micrograms of } \\
\text { sulf thiazole } \\
\text { per } 1000 \mathrm{ml} \text {. }\end{array}$ & $\begin{array}{l}\text { Microgram of } \\
p \text {-aminobenzoic } \\
\text { acid in medium }\end{array}$ & $\begin{array}{l}\text { Mg. of yeast } \\
\text { in medium }\end{array}$ & $\begin{array}{c}\text { Incubation period } \\
\text { in hours } \\
\text { necessary } \\
\text { for growt }\end{array}$ & $\begin{array}{l}\text { Micrograms of } \\
p \text {-iaminobenzoic } \\
\text { acirl found in } \\
\text { one gram }\end{array}$ \\
\hline 5,000 & 0.16 & 3.2 & 72 & 50 \\
\hline 5,000 & $0.0 \mathrm{~s}$ & 1.6 & 120 & 50 \\
\hline 1,000 & 0.04 & 0.8 & 72 & 50 \\
\hline 1,000 & 0.02 & 0.4 & 120 & 50 \\
\hline 1,000 & 0.01 & 0.2 & 168 & 50 \\
\hline 200 & 0.02 & 0.4 & 24 & 50 \\
\hline 200 & 0.01 & 0.2 & 48 & 50 \\
\hline 100 & 0.005 & 0.1 & 24 & 50 \\
\hline 100 & 0.0025 & 0.05 & 48 & 50 \\
\hline
\end{tabular}

Since, in the presence of 5,000 micrograms of sulfathiazole, $L$. arabinosus required 72 hours to show growth when 0.16 microgram of $p$-aminobenzoic acid or 3.2 milligrams of yeast was added, it follows that $3.2 \mathrm{mg}$. of yeast contained 0.16 microgram of $p$-aminobenzoic acid, or one gram contained 50 micrograms. The agreement in assay values of the different treatments li remarkable. Nevertheless, the gaps between the concentrations of the standards and of the assayed material were too large for acclinate results. When these differences were reduced, the following assior values, recorded in Table 9, were obtained:

TABle 9 - Amount of $p$-aminobenzoic Acid in Yeast

\begin{tabular}{|c|c|c|c|c|}
\hline $\begin{array}{l}\text { Micrograms of } \\
\text { sulfathiazole }\end{array}$ & $\begin{array}{l}\text { Microgram of } \\
p \text {-aminobenzoic } \\
\text { acid in medium }\end{array}$ & $\begin{array}{l}\text { Milligrams } \\
\text { of yeast } \\
\text { in medium }\end{array}$ & $\begin{array}{c}\text { Incubation period } \\
\text { in hours } \\
\text { necessary } \\
\text { for growth }\end{array}$ & $\begin{array}{l}\text { Micrograms of } \\
p \text {-aminobenzoic } \\
\text { acicl found in } \\
\text { one gram } \\
\text { of yeast }\end{array}$ \\
\hline $\begin{array}{l}200 \\
400 \\
400 \\
400\end{array}$ & $\begin{array}{l}0.00114 \\
0.0228 \\
0.0342 \\
0.057\end{array}$ & $\begin{array}{l}0.286 \\
0 . \pm 68 \\
0.908 \\
1.14\end{array}$ & $\begin{array}{l}47 \\
47 \\
30 \\
23\end{array}$ & $\begin{array}{l}40 \\
49 \\
38 \\
50\end{array}$ \\
\hline
\end{tabular}


The average of the figures in the last column is 44 micrograms of $p$-aminobenzoic acid per gram (Table 10).

TABLE 10 - p-aminobenzoic-acid Assay Values as Determined by Two organisms

\begin{tabular}{lc}
\hline Test organism & Micrograms of $p$-aminobenzoic acid per gram of yeast \\
\hline Neurospora crassa & $46 \pm 8$ \\
Lactobacillus arabinosus & $44 \pm 5.3$ \\
\hline
\end{tabular}

\section{PYRIDOXIN ASSAY}

The following organisms wëre used: Ceratostomella montium, C. pleuriannulata, Mycoderma valida, Lactobacillus arabinosus, L. casei, Leuconostoc mesenteroides, Saccharomyces carlsbergensis, and Streptococcus lactis R.

Ceratostomella montium-The various species of Ceratostomella with which the writers have worked seem to require a number of accessory factors. They grow fairly well if furnished with a suitable nitrogen source and vitamins, but even so, some species are greatly benefited by the addition of Norit-treated yeast extract. The yeast medium (p. 12) was used for all the Ceratostomella species. To each lot of 1,000 milliliters of medium was added 200 micrograms each of thiamin, riboflavin, pantothenic acid, nicotinic acid, $p$-aminobenzoic acid, 5 micrograms of biotin, 10 milligrams of inositol, and the filtrate from one gram of yeast extract twice-treated with Norit $\mathrm{A}$ at $\mathrm{pH}$ 4. In addition, 100 milligrams each of cystine and tryptophane were added to compensate for the possible shortage of these amino acids in casein hydrolysate. The nutrient medium was treated with Norit A before the vitamins were added. The $\mathrm{pH}$ of the medium was 6 before autoclaving.

The amounts of pyridoxin for the production of the standard curve were $0.0,0.025,0.05,0.1,0.2,0.4$, and 0.8 microgram per flask of 25 milliliters of solution. The amounts of yeast to be assayed were $2,4,8,16$, and 32 milligrams per flask. The period of incubation was 8 days.

Ceratostomella plouriannulata-All conditions were the same as above (Fig. 7).

Sacchuromyces carlsbergensis-The yeast medium was used, with tkiamin, calcium pantothenate, inositol, and biotin as the adder vitamins. The amounts of pyridoxin hydrochloride for the puduction of the standard curve were $0.0,0.0004,0.0008,0.0016$, $0.0032,0.0064$, and 0.0128 microgram per flask of 25 milliliters of medium. The amounts of yeast to be assayed were 0.0625 , $0.125,0.25,0.5$, and 1.0 milligram per flask.

Mycoderma valida-The medium was the same as above except that nicotinic acid was added. The amounts of pyridoxin hydrochloride for the production of the standard curve vere 0.0 , $0.00625,0.0125,0.025,0.05,0.1,0.2$, and 0.4 microgram per flask of 25 milliliters of medium (Fig. 8). The amounts of yeast to be assayed were $0.5,1,2$, and 4 milligrams per flask. 


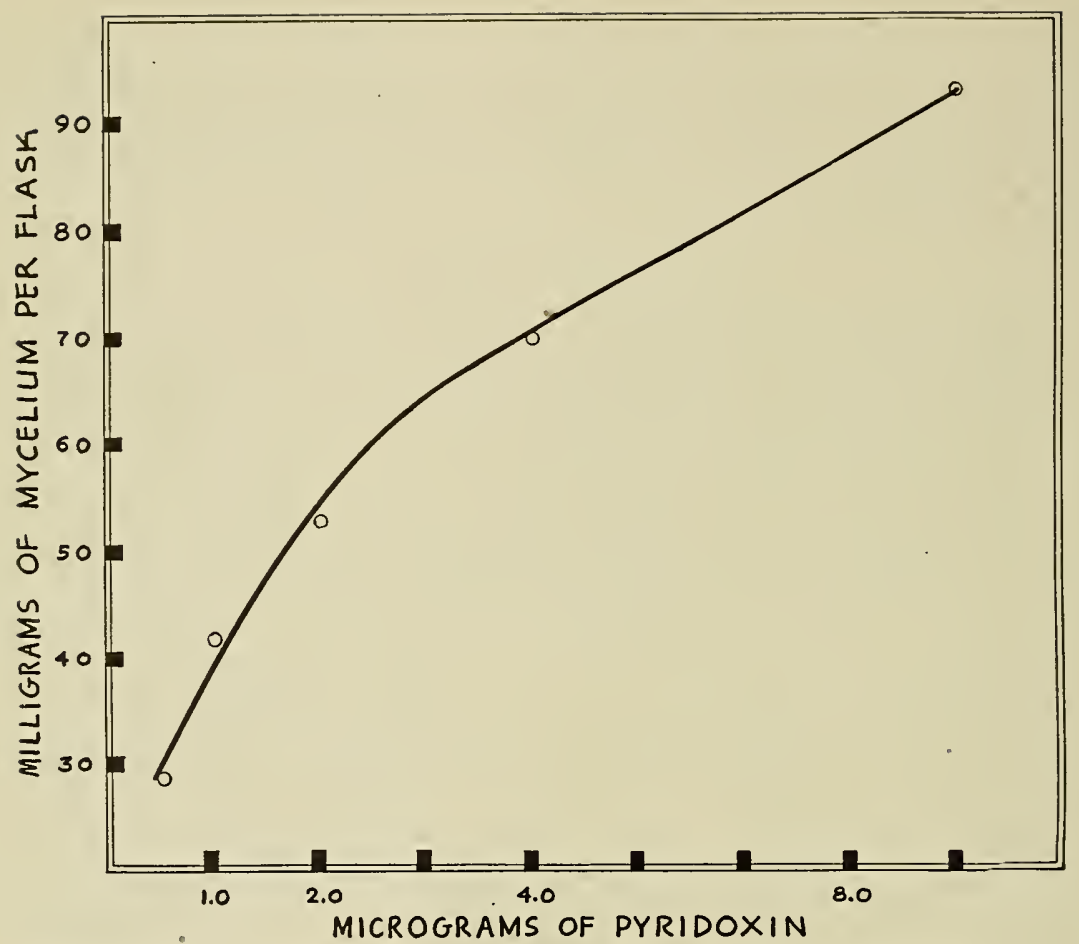

FrG. 7-Pyridoxin curve. Ceratostomella pleuriannulata test organism

Lactobacillus arabinosus and $L$. casei-The medium was the same as that used before. The amounts of pyridoxin hydrochloride for the production of the standard curve were $0.0,0.02,0.04$, $0.08,0.16,0.32$, and 0.64 microgram per flask of 10 milliliters of medium. The amounts of yeast to be assayed were $0.1,0.2$, $0.4,0.8$, and 1.6 milligrams per flask.

Leuconostoc mesenteroides-The medium was the same as that used before for this organism. The amounts of pyridoxin hydrochloride for the production of the standard curve were 0.0 , $0.1,0.2,0.4,0.8$, and 1.6 micrograms per flask of 10 r.illiliters of medium. The amounts of yeast to be assayed were $0.025,0.05$, 0.1 , and 0.2 milligram per flask.

Streptococcus lactis $R$-The Lactobacillus casei medium ana vitamins were used for this organism. The amounts of pyridoxin hydrochloride for the production of the standard curve were 0.0 , $0.1,0.2,0.4$, and 0.8 microgram per flask of 10 milliliters of medium. The amounts of yeast to be assayed were $0.0125,0.025,0.05$, and 0.1 milligram per flask.

Neurospora sitophila "Pyridoxinless"-The medium for this organism was the same as that used for $N$. crassa except that 100 micrograms of thiamin was added to each 1,000 milliliters of the 
medium, as well as 1 microgram of biotin. The amounts of pyridoxin hydrochloride added to the medium for the production of the standard curve were $0.0,0.0125,0.025,0.05,0.1,0.2,0.4$, 0.8 , and 1.6 micrograms per flask of 25 milliliters of medium. The amounts of yeast to be assayed were $2,4,8,16$, and 32 milligrams per flask.

The incubation period was 72 hours (Table 11).

TARLE 11 - Pyridoxin Assay Values as Determined by Nine Test Organisms

\begin{tabular}{lc}
\hline \hline \multicolumn{1}{c}{ Test organism } & $\begin{array}{c}\text { Microgram of pyridoxin lydrochloride } \\
\text { per gram of yeast. }\end{array}$ \\
\hline Ceratostomella montium & $27 \pm 3$ \\
Ceratostomella pleuriannulata & $25 \pm 3$ \\
Mycoderma valida & $20 \pm 3.5$ \\
Lactobacillus arabinosus & $7600 \pm 1180$ \\
Lactobacillus casei & $270 \pm 19$ \\
Leuconostoc mesenteroides & $6960 \pm 700$ \\
Neurospora sitophila & $16.8 \pm 2.5$ \\
Saccharomyces carlsbergcnsis & $9.9 \pm 1.1$ \\
Streptococcus lactis $R$ & $6500 \pm 600$ \\
\hline
\end{tabular}

BIOTIN ASSAY

Lactobacillus casei-The medium was the same as before. The amounts of biotin* for the production of the standard curve * All biotin assays were made with crystalline biotin, free acid. S. M. A. Co.

Results with biotin methyl ester proved very inaccurate.

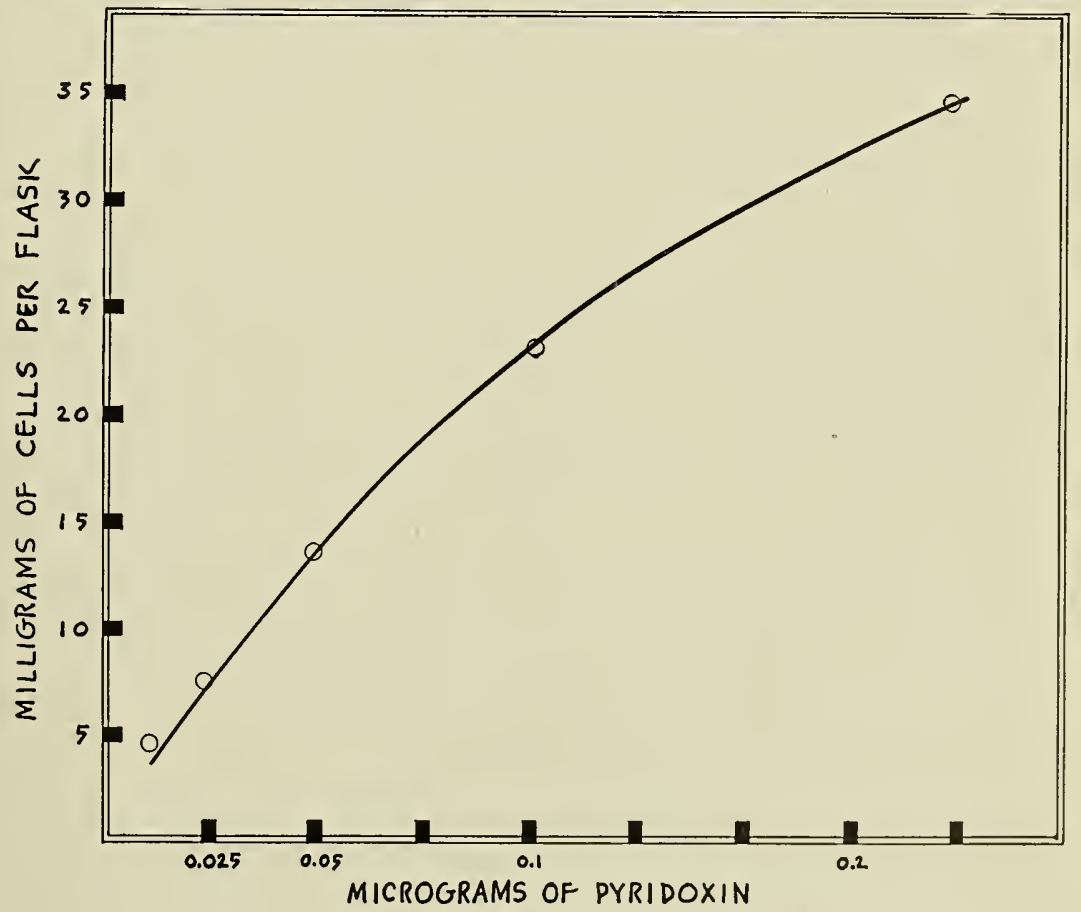

FIs. S-Pyridoxin curve. Mycoterma valida test organism 
were $0.0,0.00015625, \quad 0.0003125, \quad 0.000625, \quad 0.00125, \quad 0.0025$, 0.005 , and 0.01 microgram per flask of 10 milliliters of nutrient solution. The amounts of yeast for assaying were $0.3125,0.625$, $1.25,2.5$, and 5 milligrams per flask.

L. arabinosus-The medium was the same as before. The amounts of biotin for the production of the standard curve were $0.0,0.00015625,0.0003125,0.000625,0.00125$, and 0.0025 microgram per flask of 10 milliliters of medium. The amounts of yeast to be assayed were $1.25,2.5,5.0$, and 10 milligrams per flask.

Leuconostoc mesenteroides-The medium for this organism was the same as before. The amounts of biotin for the production of standard curve and the amounts of yeast to be assayed were the same as those for Lactobacillus casei.

S. cerevisiae "Gebrüder Mayer"-The yeast medium was used. The amounts of biotin for the production of the standard curve were $0.0,0.00025,0.0005,0.001,0.002,0.004$, and 0.008 microgram per 25 milliliters of medium. The amounts of yeast to be assayed were $1.56,3.12,6.25$, and 12.5 milligrams per flask.

Saccharomyces cerevisiae, "Old Process"-The medium for this organism was the same as before. The amounts of biotin for the production of the standard curve were $0.0,0.0000625,0.000125$, $0.00025,0.0005,0.001,0.002$, and 0.004 microgram per flask of 25 milliliters of solution. The amounts of yeast to be assayed were $0.4,0.8,1.6,3.2,6.4$, and 12.8 milligrams per flask.

Zygosaccharomyces marxianus-The medium as well as the amounts of biotin and of yeast was the same as those used for Saccharomyces cerevisice, except that nicotinic acid was added to the medium.

Debaryomyces matruchoti v. subglobosus-The medium was the same as that used for Saccharomyces cerevisiae "Old Process," except that it contained 100 micrograms of nicotinic acid in addition to other vitamins. The range of biotin for the production of the standard curve was $0.0,0.0002,0.0004,0.0008,0.0016,0.0032$, and 0.0064 microgram. The amounts of yeast to be assayed were $0.625,1.25,2.5,5.0$, and 10.0 milligrams per flask.

Ceratostomella ips 438, C. montium, C. pini 416-The medium and the incubation period were the same as those used before for the Ceratostomellas. The amounts of biotin for the production of the standard curve were the same for all three species, as follows: $0.0,0.003125,0.00625,0.0125,0.025$, and 0.05 microgram per flask of 25 milliliters of medium. The amounts of yeast to be assayed were $6.25,12.5,25,50$, and 100 milligrams per flask. The period of incubation was 8 days.

Sordaria fimicola-The yeast medium was used for this organism except that the vitamins were omitted. The medium was adjusted to $\mathrm{pH} 6.5$ before autoclaving. The amounts of biotin for the production of the standard curve were $0.0,0.005,0.0075,0.01$, $0.015,0.02,0.03,0.04,0.06,0.08,0.12$, and 0.16 microgram per 
flask of 25 milliliters of medium. The amounts of yeast to be assayed were $3.125,6.25,12.5,25,50$, and 100 milligrams per flask.

The incubation period was six days.

Rhizobinm trifolii 205-The formula of the medium for this organism was furnished by Dr. Dean Burke. It consists of the following:

Potassium dihydrogen phosphate
Magnesium sulfate
Sodium chloride
Calcium sulfate
Ferrous sulfate
Potassium nitrate
Sucrose
Thiamin hydrochloride
Distilled water

Potassium dihydrogen phosphate

Magnesium sulfate

Sodium chloride

Sucrose

Distilled water

$$
\begin{array}{cc}
1.0 & \mathrm{~g} . \\
0.2 & \mathrm{~g} . \\
0.2 & \mathrm{~g} . \\
0.1 & \mathrm{~g} \\
0.01 \mathrm{~g} . \\
1.0 \mathrm{~g} . \\
10.0 \mathrm{~g} . \\
100 \text { micrograms }
\end{array}
$$$$
1000 \mathrm{ml} \text {. }
$$

The Norit A treatment was omitted.

The $\mathrm{pH}$ of the solution was adjusted to 7 , heated, and, after filtering, readjusted to the same point. The cultures were incubated for 72 hours at $30^{\circ} \mathrm{C}$.

The amounts of biotin for the production of the standard curve were $0.0,0.00003125,0.0000625,0.000125,0.00025$, and 0.0005 microgram per flask of 10 milliliters of medium. The amounts of yeast to be assayed were $0.00375,0.0075,0.015,0.03$, and 0.06 milligram per flask.

Neurospora crassa and $N$. sitophila-The medium was the

\begin{tabular}{|c|c|c|c|}
\hline Test organism & $\begin{array}{l}\text { Microgram } \\
\text { biotin per } \\
\text { gram of seast }\end{array}$ & $\begin{array}{l}\text { Aridin } \\
\text { uncombinable* }\end{array}$ & $\begin{array}{l}\text { Ratio of aviolin- } \\
\text { combinable to } \\
\text { avilin-uncom- } \\
\text { binable form }\end{array}$ \\
\hline 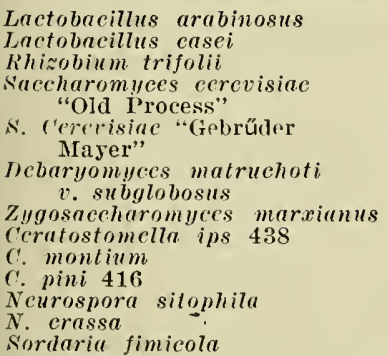 & $\begin{array}{l}0.16 \pm 0.014 \\
0.41 \pm 0.05 \\
0.58 \pm 0.05 \\
0.27 \pm 0.02 \\
0.38 \pm 0.05 \\
0.28 \pm 0.08 \\
0.53 \pm 0.05 \\
0.25 \pm 0.046 \\
0.27 \pm 0.047 \\
0.24 \pm 0.036 \\
0.32 \pm 0.025 \\
0.33 \pm 0.018 \\
0.43 \pm 0.036\end{array}$ & $\begin{array}{l}0.03 \pm 0.005 \\
0.06 \pm 0.01 \\
0.25 \pm 0.014 \\
0.06 \pm 0.005 \\
0.14 \pm 0.012 \\
0.1 \pm 0.01 \\
0.1 \pm 0.01 \\
0.1 \pm 0.01 \\
0.01 \pm 0.005 \\
0.09 \pm 0.014 \\
0.08 \pm 0.01 \\
0.08 \pm 0.01 \\
0.12 \pm 0.01\end{array}$ & 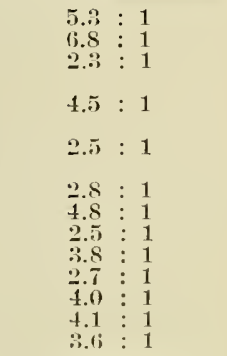 \\
\hline
\end{tabular}
same as that used before. The amounts of biotin for the production of the standard curve were 0.0, 0.000078125, 0.00015625, $0.0003125,0.000625,0.00125,0.0025$, and 0.005 microgram per flask of 25 milliliters of medium (Fig. 9). The amounts of yeast to be assayed were $0.39,0.78,1.56,3.12$, and 6.24 milligrams per flask. The incubation period was 72 hours.

TABLe 12 - Assay Values of Biotin as Determined by Thirteen Test Organisms

* The aridin treatment consisted of the following procelures: A laree cxcess of aridin was added to the biotin-containing solution and allowed to stand for a half honr; acetone was then adced to precipitate the biotin-avidin complex, the liquid rosidue was all-

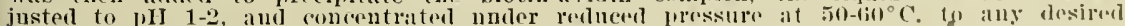
volume.

Sce Burk ant Winzler ( 
Table 12 shows that the 13 test organisms arranged themselves in several groups according to their assay values. If we assume that all substances have the same quality of "vitamers," it would be possible to state that Lactobacillus arabinosus always

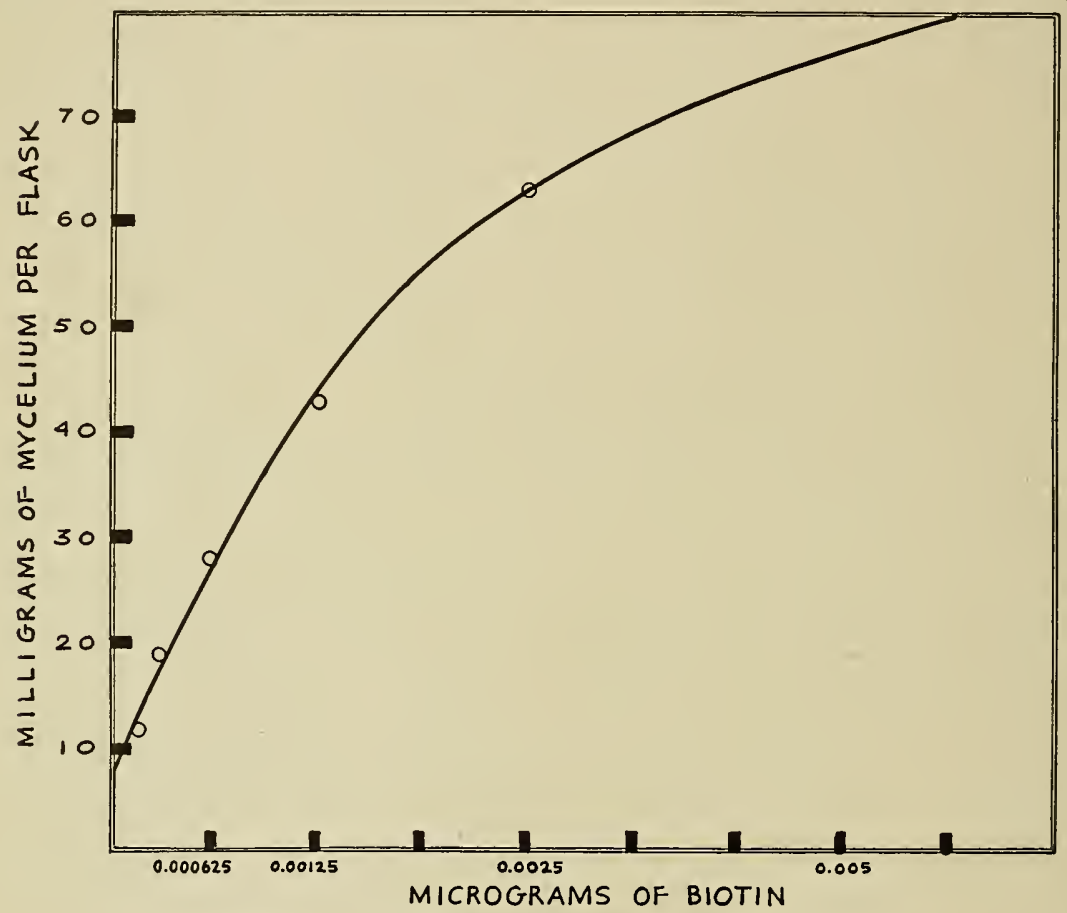

FIG. 9-Biotin curve. Neurospora sitophila test organism

should yield the lowest values, and Rhizobium trifolii or Zygosaccharomyces marxianus the highest. But such is not the case as shown by Tables 13 and 14, where values obtained with substances other than yeast are given. Table 13 gives assay values for a sample of commercial biotin concentrate of high potency.

TABLE 13 - Biotin Values of a Biotin-concentrate as obtained by the use of Seven Test Organisms

\begin{tabular}{lc}
\hline \multicolumn{1}{c}{ Test organism } & Micrograms of biotin per milligram \\
\hline Lactobacillus arabinosus & $130 \pm 3.5$ \\
Sordaria fimicola & $260 \pm 44.0$ \\
Lactobacillus casci & $290 \pm 36.0$ \\
Succhromyces ecrerisiae "Gebrüter Mayer" & $460 \pm 27.0$ \\
Saccharomyces crrcvisiac "Old Process" & $510 \pm 44.0$ \\
Debaryomyces matruchoti v. subglobosus & $510 \pm 70.0$ \\
Zygosaccharomyces marrianus & $700 \pm 78.0$ \\
\hline
\end{tabular}

Table 13 shows that again Lactobacillus arabinosus gave the lowest assay value, and Zygosaccharomyces cerevisiae the highest. However Sordaria fimicola gave the second lowest figures, while in Table 12 it ranked among the higher assaying organisms. 
Similarly, Saccharomyces cerevisiae "Old Process" gave low figures for yeast and high figures for the biotin concentrate. This shows that the nature of vitamers varies from one substance to another. This theory is given additional support by the following experiment: Three fungi and one yeast, all of them biotin requirers, were grown in a chemically defined nutrient solution; the resulting mycelium and cells were acid hydrolyzed and assayed with four representative test organisms. Table 14 gives the results.

TABLE 14 - Biotin Content of Four Fungi and one Yeast as Determined by Four Test Organisms. Values Indicated as Microgram of Biotin per Gram

\begin{tabular}{|c|c|c|c|c|}
\hline Test organism & & Organis & m assayed & \\
\hline & $\begin{array}{l}\text { Sordaria } \\
\text { fimicola }\end{array}$ & $\begin{array}{l}\text { S. Cerevisiae, } \\
\text { "Old Process" }\end{array}$ & $\begin{array}{c}\text { Neurospora } \\
\text { sitophila }\end{array}$ & $\begin{array}{c}\text { Ceratostomella } \\
\text { pini } 416\end{array}$ \\
\hline $\begin{array}{l}\text { Lactobacillus arab- } \\
\text { inosus } \\
\text { Lactobacillus casei } \\
\text { Rhizobium trifolii-205 } \\
\text { S. corevisiae } \\
\text { "Gebrürler Maser". }\end{array}$ & $\begin{array}{l}0.17 \pm 0.01 \\
0.4 \pm \pm 0.004 \\
0.16 \pm 0.007 \\
0.1 \pm \pm 0.02\end{array}$ & $\begin{array}{l}0.08 \pm 0.004 \\
0.20 \pm 0.004 \\
0.032 \pm 0.002 \\
0.055 \pm 0.0016\end{array}$ & $\begin{array}{l}0.051 \pm 0.008 \\
0.092 \pm 0.004 \\
0.015 \pm 0.001 \\
0.081 \pm 0.004\end{array}$ & $\begin{array}{l}0.17 \pm 0.02 \\
0.40 \pm 0.04 \\
0.082 \pm 0.001 \\
0.11 \pm 0.02\end{array}$ \\
\hline
\end{tabular}

Table 14 shows that Lactobacillus arabinosus failed to maintain its position as the test organism giving the lowest assay values for biotin; it was replaced by S. cerevisiae "Gebrüder Mayer," and Rhizobium trifolii 20.5; the latter organism yielded one of the highest assay values for the yeast material (Table 12).

\section{DISCUSSION}

Biologists admit freely that living things are variable and therefore most physiological responses have a wide margin of fluctuation. This is particularly true in case of microbiological assay of $B$ vitamins, where the interrelationships of the vitamins and of the accessory growth factors on the one hand, and of the specific nature of the basal medium on the other, bring many complications into the picture.

Deficiencies in the basal medium are perhaps the most important and the least understood causes of variations. When the medium is well balanced and contains all the necessary growth factors in optimum amounts, the behavior of the organisms is more nearly reproducible, becoming increasingly less predictable as conditions become unfavorable. Most test organisms used in microbiological assays have many deficiencies; some of these are known and may be provided; others are obscure. This is one reason that, in some cases, it is necessary to add to the medium certain complex organic substances to overcome food deficiencies, and to compensate for accessory factors introduced into the nutrient medium by the substances that are being assayed. Often, however, it is not possible to make such compensations; consequently the assay figures of the unknown will manifest sharp upward drifts from the standard curve. Such cases necessitate the discarding of results obtained with the larger concentrations 
of the unknown. All calculations should be based on the results obtained with the smaller amounts, whereby the obscure growthstimulating factors are reduced to such an extent as to be ineffective.

A number of organisms are able to synthesize some or all of their accessory growth factors if given sufficient time; if harvested too soon, they yield erratic results, and reproducibility becomes a hopeless task. This is illustrated by the behavior of Pythium ascophallon, which may make a satisfactory growth if only thiamin is added to the medium; biotin improves its growth; yet if harvested after an incubation of only 6 days, the amount of mycelium will not be reproducible, even though all conditions remain apparently the same; but when the incubation period is extended to 10 days, the yield becomes more uniform. Yeasts, generally speaking, behave similarly: a 24-hour growth is much more variable than a 48-hour growth; but if the medium has certain deficiencies, a 72-hour growth is more satisfactory.

It is conceivable that if all the ideal conditions for an unhampered growth of microörganisms could be provided, fluctuations would be reduced to a minimum. But, while it may be possible to control the external environment, the internal conditions of the living cell still would escape, at least to a large extent, all attempts to regulate them. Realizing this fact, as well as being aware of limitations in the refinement of technique now available, those who are engaged in microbiological assay work consider a 10 percent variation in assay figures very good, and 15 or even 20 percent permissible in some cases. Microbiological methods may not yield more exact results than animal experimentations or chemical tests, but in most cases they are much more convenient, rapid, and unquestionably more flexible. It is pertinent to note here that many of the $B$ vitamins were discovered by the use of microörganisms.

Examination of Tables 11 and 12 shows that pyridoxin and biotin yielded the most irregular results because of the presence in yeast of substances that are capable of replacing pyridoxin or biotin for some of the organisms used in this work. Figures for the thiamin assay (Table 3 ) show a remarkable uniformity despite the fact that only Pythium ascophallon requires an exogenous supply of thiamin for growth. Apparently yeast cells do not contain appreciable amounts of thiamin moieties to complicate the results. But food substances in which thiamin decomposition has taken place would undoubtedly induce higher thiamin values if Phycomyces blakesleeanus or Saccharomyces cerevisiae were used as test organisms.

The assay figures for pantothenic acid (Table 5) show that Proteus morganii gave much smaller values than the other organisms. Dorfman, Berkman, and Koser (8) found that the stimulation of respiration of Proteus morganii required the intact molecule of the pantothenic acid, and that $\beta$-alanine and $\beta, \beta$ - 
dimethyl-a-hydroxy- $\gamma$-butyrolactone," alone or in combination, could not be substituted for pantothenic acicl. We used these two substances, alone and in combination, at concentrations equivalent to 100 micrograms of calcium pantothenate per liter and observed that they failed to induce growth in Saccharomyces cerevisiae, "Old Process" and "Gebrüder Mayer," in S. carlsbergensis, and in S. oviformis. Even when these substances, in the amounts specified above, were added to 10 micrograms of calcium pantothenate per liter, there was only a slight increase in yield over that induced by 10 micrograms of calcium pantothenate alone. Therefore, it is safe to assume that neither $\beta$-alanine nor pantolactone can be considered as controlling factors insofar as the organisms mentioned above and the practical limits of microbiological assays are concerned. It is true that $\beta$-alanine may be substituted for pantothenic acid in the growth of Saccharomyces Cerevisiae "Gebrüder Mayer," but it is effective only in large amounts, approximately three times that of calcium pantothenate as shown by Pollack (16). This author also studied the behavior of Lactobacillus casei and of $L$. arabinosus but presented no data on the effect of $\beta$-alanine on their growth. However, one may infer that his results were negative. Our own tests showed that $\beta$-alanine failed to replace calcium pantothenate for $L$. case $i$ and L. arabinosus.

Since Proteus morganii gave a much smaller assay figure than the other test organisms used in this work, one may presume that yeast contains some "vitamer" effective for the other organisms used here, but not for Proteus morganii. This does not necessarily mean that Proteus morganii would continue to yield low values, if substances other than that used in this work were to be assayed.

The situation with respect to assay values for pyridoxin (Table 11) is one of wide divergence. Saccharomyces carlsbergensis shows the lowest assay value, 9.9 micrograms per gram of yeast. Ceratostomella montium, C. pleuriannulata, Mycoderma valida, and Neurospora sitophila averaged about 22 micrograms of pyridoxin per gram of yeast. If we assume that $S$. carlsbergensis responds only to pyridoxin, or its response to the various vitamers of pyridoxin is of the same order of magnitude, it would be the organism to choose for this vitamin. Concerning the second group of organisms assaying 22 micrograms, two assumptions may be made: first, at least one other compound having pyridoxin activity for these test organisms is present in the test material; second, if more than one vitamer of pyridoxin be present, the activity of these compounds for this group of test organisms is about the same. Lactobacillus casei is unique in its position; unlike Streptococcus lactis $R$, it grows in the presence of unautoclaved pyridoxin, but it is obvious that our sample of yeast does not contain 270 micrograms of pyridoxin per gram, therefore $L$. casei responds to some vitamer $(\mathrm{s})$ of pyridoxin.

* Obtained through courtesy of Dr. R. T. Major of Merck and Company. 
When pyridoxin is subjected to prolonged autoclaving, it induces better growth in $L$. casei, thus substantiating the theory that this organism responds to some modification of pyridoxin produced by this treatment. However, the question may be raised as to why Streptococcus lactis $R$ should give an assay value of 6,500 micrograms per gram, whereas $L$. casei gives only 270 . The logical assumption is that the so-called "pseudopyridoxin" (see introduction) is not one compound, but a group of compounds.

Since this paper was submitted for publication, E. E. Snell (20) published a very illuminating communication on the "pseudopyridoxin" question. Briefly, two compounds derived from pyridoxin have been shown to possess vitamin activity and, indeed, to a much greater extent than pyridoxin itself for some organisms.

These vitamers of pyridoxin have the activities shown in the following table taken from Snell's paper (loc. cit.).

\begin{tabular}{lccc}
\hline \hline \multirow{2}{*}{ Organism } & \multicolumn{3}{c}{ Comparable activity } \\
\cline { 2 - 4 } & Pyridoxin & Pyridoxal & Pyridoxamine \\
\hline S. lactis $R$. & 1.0 & $5000-8000$ & $6000-9000$ \\
L. casei & 1.0 & $1000-1500$ & $3-10$ \\
S. carlsbergensis & 1.0 & $0.9-1.4$ & $0.8-1.3$ \\
\hline
\end{tabular}

If one now considers the assay value of 270 given by $L$. casei, it is possible that the "pseudopyridoxin" in our yeast sample consisted of a mixture of pyridoxal and pyridoxamine, with pyridoxamine being present in the greater amount. (One may regard for the moment the ever-present possibility that there are still other members of the "pseudopyridoxin" complex still undiscovered). If one now considers the assay value given by $S$. lactis $R$, it will be seen to be less than 1000 times as great as that given by S. curlsbergensis. Thus it is probable that less than one sixth of the pyridoxin in our yeast sample consisted of pyridoxamine or pyridoxal. Nevertheless, the possibility of other compounds having "pseudopyridoxin" activity is still an open question.

Since the comparative values of pyridoxal and pyridoxamine for Ceratostomella montium, C. pleuriannulata, Mycoderma valida. Neurospora sitophila, and-Lactobacillus arabinosus are not yet known, it would be without point to speculate further concerning these organisms at this time.

The recent paper of Johnson (11) presents data in apparent conflict with those of Snell and, in some particulars, with ours. According to Johnson, L. casei cannot utilize pyridoxin, but only "pseudopyridoxin." Our results showing $L$. casei to respond to an unautoclaved alcoholic solution of pyridoxin, when this is added to a previously sterilized medium, inclines us to view Johnson's results with reserve. See also Snell (loc. cit.). The probable cause of divergence of views on the utilization of pyridoxin by $L$. casei lies in the low concentration of pyridoxin used by Johnson. Likewise the failure of Johnson to obtain growth of S. carlsbergensis on "pseudopyridoxin" is not confirmed by the findings of Snell (loc. cit.) insofar as pyridoxal and pyridoxamine are concerned. 
However, as we have already remarked, there may be reasons for supposing that still other members of the "pseudopyridoxin" complex remain unknown at the present time. Johnson found Leuconostoc mesenteroides to respond to "pseudopyridoxin"; the high assay (Table 9) value given by this organism confirms Johnson.

Carpenter and Strong (5) have shown that hydrogen-peroxide treatment of pyridoxin enhances its activity for Lactobacillus casei. The "pseudopyridoxin" so formed is not active towards yeast (strain not stated) ; or, the activity of the "pseudopyridoxin" for the yeast was the same as that of pyridoxin. They also found $L$. case $i$ to respond to pyridoxin sterilized by filtration through a Seitz funnel; $i$. e., to pyridoxin per se.

Table 12 shows that the situation with regard to biotin is no less perplexing. Lactobacillus arabinosus gave an assay value of 0.16 ; Ceratostomella pini, C. montium, C. ips, Debaryomyces matruchoti v. subglobosus, and Saccharomyces cerevisiae "Old Process" may be grouped together with an average assay value of 0.26 ; Neurospora sitophila, N. crassa, and Saccharomyces cerevisiae "Gebrüder Mayer" form a third group with an average of 0.33 ; Lactobacillus casei and Sordaria fimicola are placed in a fourth group with an average of 0.42 , while Zygosaccharomyces marxianus and Rhizobium trifolii are in the last group with an average of 0.55 . When the avidin-uncombinable portion is deducted, the organisms regroup themselves as follows: Lactobacillus arabinosus, Ceratostomella ips, C. montium, and Debaryomyces matruchoti $v$. subglobosus averaged 0.15 ; Ceratostomella montium, Saccharomyces cerevisiae "Old Process" and "Gebrüder Mayer," Neurospora crassa, and $N$. sitophila averaged 0.23 ; Lactobacillus casei and Rhizobium trifolii averaged 0.34 , while Zygosaccharomices marxianus still remained at the top of the list with a figure of 0.43 . It is obvious that the yeast sample assayed by us contains a number of compounds capable of replacing biotin for some organisms.

While du Vigneaud, Dittmer, Hague, and Long (9) found that pimelic acid and biotin could replace each other in the growth of $C$. diphtheriae, Wright (22) states that pimelic acid was ineffective in case of L. casei, and Robbins and Ma (17) found it to be devoid of biotin activity for the three species of Ceratostomella used in this work. We observed that Sordaria fimicola failed to grow when pimelic acid was substituted for biotin. Recently Melvilie, Dittmer, Brown, and du Vigneaud (15) reported that Saccharomyces cerevisiae, strain 139, grew equally well in a medium where desthiobiotin replaced biotin, while Lactobacillus cresei failed to grow. We found that desthiobiotin replaced biotin for 25 strains of Saccharomyces cerevisice, as well as 10 other organisms including Debaryomyces matruchoti v'. sulyglobosus, Zugosaccharomyces marxianus, Ceratostomella ips 438, C. montium. Neurospora crassa, and N. sitophila. On the other hand. Ceratostomella pini 416, Sordaria fimicola. Lactobacillus casei. L. arabinosus, and Rhizobium trifolii failed to respond to desthiobiotin. It 
is probable that this substance is not present in yeast, at least not in sufficient amounts, to be a factor. For instance, both Lactobacillus arabinosus and Ceratostomella ips 438 assayed approximately the same amount of avidin-combinable biotin, yet one of them cannot utilize desthiobiotin (which is avidin-combinable), while the other can. Similarly, Lactobacillus casei is unable to grow in the presence of desthiobiotin when this substance replaces the biotin of the medium, yet it gave a very high assay figure. It is obvious that not only the avidin-combinable but also the avidinuncombinable forms contain a number of vitamers which may be more or less closely related.

Two biotin vitamers, desthiobiotin-diaminocarboxylic acid and imidazolidone valeric acid have been shown by Dittmer and du Vigneaud (6) to possess 10 and 0.0017 percent respectively of the activity of biotin for a yeast (strain not stated, though presumably strain 139). These compounds are active neither as growth promoters nor as antibiotins for $L$. casei. Biotin sulfone ( 7 ) is less active than biotin for yeast (strain 139) and strongly inhibitory for $L$. casei and $L$. arabinosus.

Burk and Winzler (l.c.) state that a strain of yeast converted du Vigneaud's diaminocarboxylic acid to avidin-combinable biotin; similarly "miotin" and "tiotin" were converted to avidin-combinable form. The fact that yeast cells are capable of regenerating the avidin-uncombinable "vitamers" suggests the possibility that at least some "vitamers" may be degradation products of biotin. However, at the present stage of our knowledge concerning this complicated situation, we do not know whether living cells merely link the secondary compounds of biotin into avidin-combinable forms as, for instance, Phycomyces blakesleeanus links pyrimidine and thiazole to produce thiamin, or whether they are capable of synthesizing some missing factor and producing the complete biotin molecule. Since such animals as rats and mice do not seem to respond to biotin "vitamers," their value in biotin assay becomes at once apparent.

The question now arises as to the place and the reliability of microbiological methods in vitamin $B$ assays. We have seen that in case of pyridoxin and biotin, the situation is chaotic and is likely to remain so for some time to come, if not indefinitely. We are faced not only with many different "vitamers," which vary qualitatively and quantitatively in different substances, but also with the possibility that a given vitamin may exist in the form of different isomers, each with specific chemical, physical, and biological properties. According to Kögl and ten Ham (12), for instance, $a$-biotin (from egg yolk) and $\beta$-biotin (from liver) have different structural formulae, different melting points and optical rotation. It is possible that some of the substances which we assume to be "vitamers" may, in reality, be true vitamins. But as yet having no methods of demonstrating this, we can merely say that it is unwise to assume that a given vitamin always occurs in one specific form, or as one definite compound in the tissues of 
all plants and animals. Nor is it safe to suppose that even the best of extraction methods at our disposal can remove all forms of the vitamin; or, having removed, can present them to all test organisms in a uniformly available state.

In view of the data presented in Tables 12, 13, and 14, it seems doubtful that we can select one test organism as the most satisfactory for assaying the biotin content of all substances; nor is there much hope of ever finding such an organism merely by multiplying the substances to be assayed and the oganisms with which to make these assays. It will be comparatively less complicated to find the most satisfactory organism to assay the biotin content of one specific substance, or perhaps a group of substances; but that seems to be just about as far as we hope to go.

The other members of $\mathrm{B}$ vitamins, thiamin, inositol, nicotinic acid, $p$-aminobenzoic acid, riboflavin, and to some extent pantothenic acid have shown no tendency to vary greatly. This does not mean that they will continue to yield satisfactory assay figures, no matter how numerous might be the test organisms and the materials to be assayed. The low value given for pantothenic acid by Proteus morganii is pertinent. It may be that this organism possesses a low efficiency to utilize fully the pantothenic acid content of the particular yeast sample assayed in this work, and that it may give high assay values if used to test some other substances for pantothenic acid. It is a well-known fact that biotin methyl ester cannot be utilized as a source of biotin by a number of organisms, while in the case of others it replaces biotin more or less completely. It is true that biotin methyl ester may not be present in nature, but who can say, in view of the behavior of the test organisms used in this work, that there are not other biotin compounds of similar nature? Similarly, how can one be certain that pantothenic acid exists universally as the same compound, possessing the same immutable properties? This may apply equally well to the other vitamins, but unless a very large number of test organisms and test substances are used, this question will remain unanswered.

\section{SUMMARY}

This work has two objectives: first, to distinguish the "vitamer" effect from the vitamin effect; second, to bring together and to extend the more promising methods of microbiological assay.

A commercial sample of dry yeast was assayed throughout this work by a great many test organisms.

Of the four test organisms used to assay pantothenic acid, Proteus morganii gave the lowest value, while Lactobacillus casei. L. arabinosus, and S. cerevisiae "Gebrüder Mayer" assayed nearly" twice as much pantothenic acid as Proteus morganii and presumably responded to some "vitamer" of pantothenic acid.

Saccharomyces carlsbergensis yielded the lowest assay values for pyridoxin, 9.9 micrograms per gram of yeast as against 16.8 
for Neurospora sitophila; 20-27 for Ceratostomella montium, $C$. pleuriannulata, and Mycoderma valida: 270 for Lactobacillus casei, and from 6,500 to 7,600 micrograms for Streptococcus lactis $R$, Leuconostoc mesenteroides, and Lactobacillus arabinosus. This indicates the presence in yeast of more than one "vitamer" of pyridoxin.

The 13 test organisms used to assay biotin gave figures varying from 0.16 to 0.58 microgram per gram. The avidin-uncombinable portion varied from 0.03 to 0.25 microgram per gram, showing that this portion also consists of more than one substance.

When substances other than yeast were assayed for biotin, the test organisms failed to maintain the same order in their assay values; those giving low values for yeast yielded high figures, and those that gave high values, yielded low figures. This shows that there are not only biotin "vitamers" of different quality as well as quantity, but perhaps diverse biotin isomers in different substances.

Pythium ascophallon, Phycomyces blakesleeanus, and Saccharomyces cerevisiae "Old Process" assayed about 500 micrograms of thiamin per gram of veast. In case of processed foods where there might be degradation products of thiamin, Pythium ascophallon should be preferred because it responds only to the thiamin molecule; otherwise, Phycomyces is the most satisfactory.

Lactobacillus casei, L. arabinosus, Leuconostoc mesenteroides, and Zygosaccharomyces marxianus assaved about 300 micrograms of nicotinic acid per gram of yeast and seem to be equally satisfactory.

Neurospora crassa " $p$-aminobenzoicless" strain, and Lactobacillus arabinosus assayed about 45 micrograms of this vitamin per gram of yeast.

Saccharomyces cerevisiae "Old Process" and Neurospora crassa. "Inositolless" were the two organisms used for inositol assay.

Lactobacillus casei was the only organism used for assaying ribofìavin.

Old, improved, and new methods of microbiological assay are described in some detail. The application of microbiological assay methods to the vitamer situation is discussed with especial reference to pyridoxin and biotin.

\section{LITERATURE CITED}

(1) Beadle, G. W.

An Innsitolless mutant strain of Neurospora and its use in bioassays.

Jour. Biol. Chem. 156: 683-689. 1944.

(a) Borarnick, M. R.

Substitution of heated asparagine-glutamate mixture for nicotinamide as a growth factor for Bacterium dysenteriae and other microörganisms. Jour. Biol. Chem. 1.jS: 151-161. 1943.

Isolation of nicotinamide formed from asparagine and glutamic acic.. Jour. Biol. Chem. 153: 1-3. 1944 
(y) Burk, Dean, and R. J. Winzler.

Heat labile, avidin-uncombinable, species-specific and other vitamers of biotin. Sci. 97 : 57-60. 1943.

(j) Carpenter, L. E., and F. M. Strong.

Determination of pyridoxin and pseudo-pyridoxin. Arch. Biochem. ?: 375-38s. 1944.

(6) Dittmer, K., and V. du Vigneaud.

Antibiotins. Sci. 100: 129-131. 1944.

(7) …........, ..........., P. György, and C. S. Rose.

A study of biotin sulfone. Arch. Biochem. 4: 229-242. 1944.

(8) Dorfman, Albert, Sam Berkman, and Stewart A. Koser.

Pantothenic acid in the metabolism of Proteus morganii. Jour. Biol. Chem. 141: 292-300. 1942.

(9) du Vigneaud, Vincent, K. Dittmer, E. Hagne, and B. Long.

The growtl-stimulating effect of biotin for diphtheria bacillus in the absence of pimelic acid. Sci. 96: 186-187. 1942.

(10) Isbell, H., J. G. Wooley, R. E. Butler, and W. H. Sebrell.

A bacterial method for nicotinamide and related substances in blood, urine and spinal fluid. Jour. Biol. Chem. 139: 499-510. 1941.

(11) Johnson, B. Conner.

Microbiological differentiation of pyridoxin and pseudo-pyridoxin.

Proc. Soc. Exp. Biol. and Med. 55: 199-201. 1944.

(12) Kögl, F., and E. J. ten Ham.

Zur kenntnis des $B$-biotins. 34. Nitteilung ïber pflänzliche Wachstum. stoffe, Zeit. Physiol. Chem. 279: 140-152. 1943.

(13) Krehl, W. A., F. M. Strong, and C. A. Elvejhem.

Determination of nicotinic acid. Ind. and Eng. Chem. Anal. Ed. 15: 471-475. 1943.

(1.1) Landy, M., and D. M. Dicken.

A microbiological assay method for six $\mathrm{B}$ vitamins using Lactobacillus casei and a medium of essentially known composition. Jour. Lab. Clin. Med. 2\%: 1086-1092. 1942.

(15) Melville, Donald B., Karl Dittmer, George B. Brown and Vincent du Vigneaud. Desthiobiotin. Sci. 98: 497-499. 1943.

(16) Pollack, Maxwell A.

Growth effects of $a$-methyl homologs of pantothenic acid and $B$-alanine. Jour. Amer. Chem. Soc. 6i: 1335-1339. 1943.

(1\%) Robbins, Wm., and Roberta Ma.

Pimelic acid, biotin, and certain fungi. Sci. .96: 406-407. 1942.

(18) Snell, Esmund E., B. M. Guirard, and R. J. Williams.

Occurrence in natural products of a physiologically active metabolite of pyridoxin. Jour. Biol. Chem. 1.3: 519-530. 1942.

$(19)$

$(20)$

Effect of heat sterilization on growth-promoting activity of pyridoxine for streptococcus lactis R. Proc. Soc. Exp. Biol. and Med. .1: 356-35S 1943.

The vitamin activities of "pyridoxal" and "pyridoxamine." Jour. Biol. Chem. 15.: 313-31.4. 1944.

(21) Tatum, E. L., and G. W. Beadle.

Specificity of Neurospora crassa tor $p$-aminobenzoic acial. Proc. Nat. Acad. Sci. (U. S. A.) 28: 234-243. 1942.

(2?) Wright, L. D.

Inability of pimelic acid to replace biotin as growth factor for Lactobacillus casei. Proc. Soc. Exp. Biol. and Med. 51: 27. 1942.

(23) Wyss, O., V. G. Lilly, and L. H. Leonian.

The effect of $\mathrm{pH}$ on the availability of $p$-aminobenzoic acid to Yrcurospora crassa. Sci. 99: 18-19. 1944. 


